\title{
Perturbations in the Carotenoid Biosynthesis Pathway in Tomato Fruit Reactivate the Leaf-Specific Phytoene Synthase 2
}

\author{
Uri Karniel, Nastacia Adler Berke, Varda Mann and Joseph Hirschberg*
}

Department of Genetics, Alexander Silberman Institute of Life Sciences, The Hebrew University of Jerusalem, Jerusalem, Israel

\section{OPEN ACCESS}

Edited by:

$\mathrm{Li} L \mathrm{Li}$

Cornell University, United States

Reviewed by:

Laura Perez Fons,

University of London,

United Kingdom

Ralf Welsch,

University of Freiburg, Germany

${ }^{*}$ Correspondence:

Joseph Hirschberg

hirschu@mail.huji.ac.il

Specialty section:

This article was submitted to

Plant Metabolism and

Chemodiversity,

a section of the journal

Frontiers in Plant Science

Received: 28 December 2021

Accepted: 27 January 2022

Published: 25 February 2022

Citation:

Karniel U, Adler Berke N, Mann V and Hirschberg J (2022) Perturbations in the Carotenoid Biosynthesis Pathway

in Tomato Fruit Reactivate the Leaf-

Specific Phytoene Synthase 2.

Front. Plant Sci. 13:844748.

doi: $10.3389 /$ fpls.2022.844748
The accumulation of the red carotenoid pigment lycopene in tomato (Solanum lycopersicum) fruit is achieved by increased carotenoid synthesis during ripening. The first committed step that determines the flux in the carotenoid pathway is the synthesis of phytoene catalyzed by phytoene synthase (PSY). Tomato has three PSY genes that are differentially expressed. PSY1 is exclusively expressed in fruits, while PSY2 mostly functions in green tissues. It has been established that PSY1 is mostly responsible for phytoene synthesis in fruits. Although PSY2 is found in the chromoplasts, it is inactive because loss-of-function mutations in PSY1 in the locus yellow flesh ( $r$ ) eliminate carotenoid biosynthesis in the fruit. Here we demonstrate that specific perturbations of carotenoid biosynthesis downstream to phytoene prior and during the transition from chloroplast to chromoplast cause the recovery of phytoene synthesis in yellow flesh $(r)$ fruits without significant transcriptional changes of $P S Y 1$ and $P S Y 2$. The recovery of carotenoid biosynthesis was abolished when the expression of $P S Y 2$ was silenced, indicating that the perturbations of carotenoid biosynthesis reactivated the chloroplast-specific PSY2 in fruit chromoplasts. Furthermore, it is demonstrated that PSY2 can function in fruit chromoplasts under certain conditions, possibly due to alterations in the plastidial sub-organelle organization that affect its association with the carotenoid biosynthesis metabolon. This finding provides a plausible molecular explanation to the epistasis of the mutation tangerine in the gene carotenoid isomerase over yellow flesh.

Keywords: carotenoid biosynthesis, phytoene synthase, Solanum lycopersicum, fruit, chromoplast, retrotransposons

\section{INTRODUCTION}

Carotenoid pigments are naturally occurring isoprenoid molecules that perform essential functions in plants and animals (Cuttriss et al., 2011). They are indispensable in all photosynthetic organisms where they play roles in photosynthesis, both in light-harvesting and protection against damages caused by excessive light energy (Telfer, 2005; Hashimoto et al., 2016). Carotenoids are vital components in human nutrition for their health benefits as antioxidants and precursors of vitamin A (Eggersdorfer and Wyss, 2018; Rodriguez-Concepcion et al., 
2018; Von Lintig and Quadro, 2020). In addition to furnishing flowers and fruits with colors, carotenoids also serve as precursors in the biosynthesis of growth regulators and developmental signals, such as abscisic acid (ABA) and strigolactone (Walter et al., 2015; Hou et al., 2016; Wang et al., 2020). In plants, carotenoids are synthesized in plastids from isopentenyl pyrophosphate (IPP)-derived geranylgeranyl diphosphate (reviewed in: Hirschberg, 2001; Ruiz-Sola and RodríguezConcepción, 2012; Nisar et al., 2015; Rosas-Saavedra and Stange, 2016). The first committed step in the biosynthesis pathway is phytoene formation from two molecules of geranylgeranyl pyrophosphate (GGPP) catalyzed by the enzyme PSY (Figure 1). In the subsequent steps, the production of all-trans-lycopene from 15-cis-phytoene involves four enzymes: phytoene desaturase (PDS), $\zeta$-carotene isomerase (ZISO), $\zeta$-carotene desaturase (ZDS), and carotenoid isomerase (CRTISO;

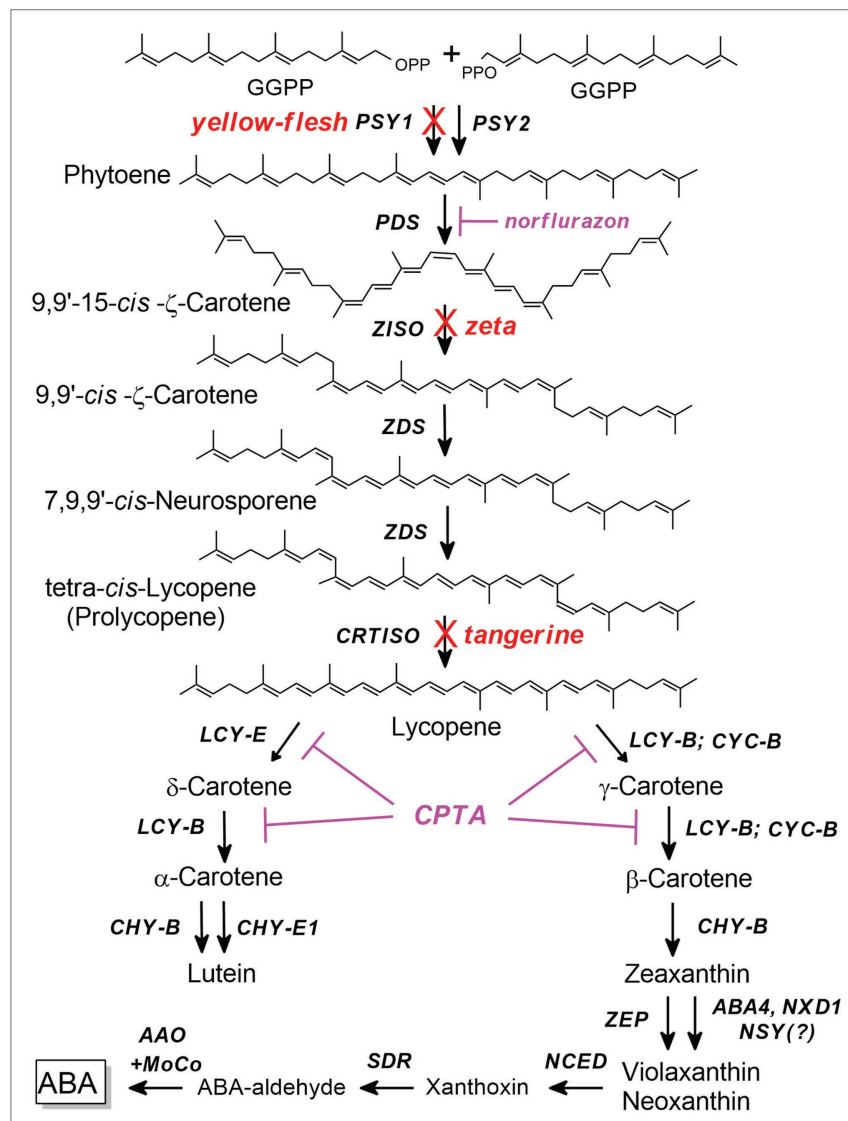

FIGURE 1 | The carotenoid biosynthesis pathway in tomato. AAO, abscisic aldehyde oxidase; ABA, abscisic acid; ABA4, involved in neoxanthin synthesis; $\mathrm{CHY}$-B, $\beta$-carotene hydroxylase, $\mathrm{CHY}$-E- $\varepsilon$-carotene hydroxylase, CRTISO, carotene isomerase; CYC-B, chromoplasts-specific lycopene $\beta$-cyclase; GGPP, geranylgeranyl diphosphate; LCY-B, lycopene $\beta$-cyclase; LCY-E, lycopene $\varepsilon$-cyclase; MoCo, molybdenum cofactor; NCED, 9-cisepoxycarotenoid dioxygenase; NSY, presumed neoxanthin synthase; NXD1, involved in neoxanthin synthesis; PDS, phytoene desaturase; PSY, phytoene synthase; SDR, short-chain alcohol dehydrogenase/reductase; ZDS, $\zeta$-carotene desaturase; ZEP, zeaxanthin epoxidase, ZISO, $\zeta$-carotene isomerase. Mutations that interrupt the pathway are indicated in red and inhibitors in magenta.
Figure 1). PDS and ZDS introduce four double bonds by catalyzing two symmetric dehydrogenation reactions to yield two cis-configured molecules, $\zeta$-carotene and lycopene, respectively (Isaacson et al., 2004). ZISO is required for cisto-trans conversion of the $15-15^{\prime}$ cis double bond in tri-cis$\zeta$-carotene (Chen et al., 2010). Another isomerase, CRTISO, produces all-trans-lycopene from tetra-cis-lycopene ("prolycopene"; Isaacson et al., 2002; Park et al., 2002). Next, the linear molecule lycopene undergoes cyclization either by LCY-b or CYC-b to create a $\beta$-ring or LCY-e to form an $\varepsilon$-ring (Cunningham et al., 1996; Pecker et al., 1996). Hydroxylation of the cyclized carotenes produces the xanthophylls (oxygenated carotenoids) lutein in the $\varepsilon$-branch, and zeaxanthin, violaxanthin, and neoxanthin in the $\beta$-branch.

The tomato (Solanum lycopersicum) is a leading model in fleshy fruit ripening research and a favorite plant for studying the regulation of carotenoid biosynthesis (reviewed in: Fray and Grierson, 1993b; Fraser et al., 1994; Giovannoni, 2001; Bramley, 2002; Alexander and Grierson, 2002; Giovannoni, 2007; Klee and Giovannoni, 2011; Liu et al., 2015; Li et al., 2019). During the first 5-7 weeks after anthesis, the developing tomato fruit is green as its tissues contain chloroplasts. At the "breaker" stage of ripening, the mature green fruit undergoes a dramatic color change due to the degradation of chlorophyll and a concomitants accumulation of lycopene. Increased synthesis and accumulation of carotenoids in high concentration are linked to a chloroplast-to-chromoplast transition (Maass et al., 2009; Lado et al., 2016; Sun et al., 2018; Llorente et al., 2020), and involves extensive changes in gene expression (Alba et al., 2005; Klee and Giovannoni, 2011; Giovannoni et al., 2017). The synthesis of phytoene is a rate-limiting step that determines the flux of carotenoid biosynthesis. Therefore, PSY is a key regulating enzyme of the pathway (Bramley, 2002; RodriguezVillalon et al., 2009; Ruiz-Sola and Rodríguez-Concepción, 2012; Enfissi et al., 2017). While Arabidopsis thaliana has a single PSY gene, in some other plant species PSY constitutes a small gene family that are distinctly expressed in different organs (Gallagher et al., 2004; Giorio et al., 2008; Li et al., 2008; Welsch et al., 2008; Li et al., 2009; Arango et al., 2010; Qin et al., 2011; Lopez-Emparan et al., 2014; Ahrazem et al., 2019; Wei et al., 2020; Wang et al., 2021). The tomato genome contains three PSY genes that show distinct expression patterns (Fraser et al., 2007; Giorio et al., 2008). The amino acid sequences of PSY1 and PSY2 are highly conserved. However, although they have similar enzymatic properties, they differ in cofactor requirement and $\mathrm{K}_{\mathrm{m}}$ for GGPP (Fraser et al., 2000). It was demonstrated that PSY2 is enzymatically more efficient than PSY1 when expressed in Arabidopsis leaves or E. coli (Cao et al., 2019). PSY2 functions in leaves and other green tissues that contain chloroplasts (Giorio et al., 2008). PSY3 is expressed in roots where the carotenoid-derived hormones abscisic acid (ABA) and strigolactones are synthesized (Walter et al., 2015; Stauder et al., 2018). The gene responsible for carotenoid biosynthesis in chromoplast-containing fruits is $P S Y 1$. Its transcription is upregulated at the "breaker" stage of fruit ripening and remains high till the ripe stage. Although PSY2 is also expressed to some extent in the fruit, it does 
not contribute to carotenoid synthesis in this organ (Fraser et al., 1999). This is evident in the recessive mutation yellow flesh that impairs the PSY1 gene and abolishes phytoene synthesis in fruits (Fray and Grierson, 1993a; Fraser et al., 1999; Kachanovsky et al., 2012). Fruits of the yellow flesh mutant are yellow due to the pigment naringenin chalcone, and they contain negligible amounts of carotenoids. Therefore, the locus was named $r$ (R for red, $\mathrm{r}$ for non-red or yellow; McCue, 1952). The oldest known yellow-flesh allele, named $r^{2997}$, was described as a "spontaneous" mutation (Chetelat, 2002). It has been shown that this allele eliminates the transcription of PSY1 in fruit (Kachanovsky et al., 2012). Another mutation, tangerine (locus $t$ ), has orange fruit flesh due to the accumulation of tetracis-lycopene ("prolycopene") as a result of a mutation in the gene encoding the CRTISO enzyme (Isaacson et al., 2002). Because this reaction occurs downstream to phytoene in the carotenoid biosynthesis pathway (Figure 1), blocking phytoene synthesis by yellow flesh should be epistatic to tangerine. However, several studies in the 1950s reported that the mutation tangerine is epistatic to yellow-flesh $r^{2997}$ since the phenotype of the double mutant $t r$ was typical of tangerine (Tomes et al., 1953). Previously, we have demonstrated that under the genetic background of tangerine, transcription of PSY1 in $r^{2997}$ was partially recovered (Kachanovsky et al., 2012). It was suggested that this phenomenon was induced by the increased concentration of cis-carotenes (Kachanovsky et al., 2012). However, the molecular mechanism underlying the epistasis of tangerine over $r^{2997}$ has remained unclear because the exact nature of the mutation in this allele has not been identified. Here we characterize the mutation in yellow flesh $r^{2997}$ caused by an insertion of a retrotransposon in the coding region of PSY1 and describe its effects on the transcription of the gene. Characterization of additional yellow flesh alleles and obstructing the carotenoid biosynthesis pathway downstream to phytoene indicate that the epistasis phenomenon is mainly due to the activation of the chloroplast phytoene synthase, PSY2, otherwise inactive in tomato fruit.

\section{MATERIALS AND METHODS}

\section{Plant Material and Growth Conditions}

The tomato (Solanum lycopersicum) varieties M82 and Rutgers served as a reference "wild-type." The tangerine $t^{3002}$ and yellow flesh $r^{2997}$ mutants and the wild species S. pimpinellifolium accession LA1589 were obtained from the Tomato Genetics Resource Center (University of California, Davis, CA). Mutants $t^{3406}, r^{3756}$, and $z^{2803}$ were isolated from the variety M82 following mutagenesis and screening (Menda et al., 2004). Introgression line IL3-2, which carries a single chromosomal segment from S. pennellii (LA716) in the genetic background M82 (Eshed and Zamir, 1995), was obtained from Prof. Zamir (The Hebrew University of Jerusalem, Israel). Virus-induced gene silencing (VIGS) experiments were carried out in a transgenic Moneymaker line overexpressing the Delila (Del) and Rosea1 (Ros1) Myb transcription factors from Antirrhinum majus under control of the fruit-specific promoter E8 (Butelli et al., 2008; Orzaez et al., 2009). Plants were grown in the greenhouse as previously described (Neuman et al., 2014).

\section{DNA Extraction and Genotyping}

DNA was extracted from approximately $15 \mathrm{mg}$ of young leaves as previously described (Eshed and Zamir, 1995). Homozygous F2 plants from crosses between the different carotenoid mutants were identified by visual screening and confirmed through DNA genotyping. The tangerine alleles $t^{3406}$ and $t^{3002}$, and the zeta mutant $z^{2083}$ were identified by the virescence appearance of their shoots and the tawny flower color typical of tangerine. The genotyping of the homozygous yellow flesh mutants IL3-2 $\left(r^{\mathrm{sp}}\right), r^{2997}, r^{3756}$, and Delila + Rosea (DR) was confirmed by polymerase chain reactions (PCR) amplification using the following primers: For PSY1 in IL3-2, 5'-AATACTTTTAGGGTCAAACAATTAA- $3^{\prime}$ (forward) and 5'-AAAAATTGACCCACATTGAAAAA- $3^{\prime}$ (reverse). Due to a deletion of $672 \mathrm{bp}$ in the PSY1 from S. pennellii and its introgression line IL3-2, the PCR amplification yielded a $1065 \mathrm{bp}$ fragment in the wildtype tomato S. lycopersicum and 393 bp in the IL3-2 introgression line. For PSY1 in $r^{2997}$, the primers 5'-CGGGAGTCATTAGCATAGTTCC- $3^{\prime}$ (forward) and $5^{\prime}$ - CGAGGCATAGGAATTTGGTG-3' (reverse) were used for PCR amplification. A $5 \mathrm{~kb}$ insertion in the PSY1 from $r^{2997}$ generates a fragment of $5,326 \mathrm{bp}$ in $r^{2997}$ and $447 \mathrm{bp}$ in the wild-type. Amplification of such a large fragment by PCR was possible using the KAPA HiFi HotStart ReadyMix kit \#KK2601 (Roche). For PSY1 in $r^{3756}, \quad 5^{\prime}$-CGAGGCATAGGAATTTGGTG-3' (forward) and 5'-ACCTATCTAAGGCTGCCGGGGTAATA-3' (reverse). The PCR product was sequenced to identify the presence of a transition mutation changing codon 151 from Trp to an early stop codon (Kachanovsky et al., 2012).

The presence of the transgenic $D R$ genes was confirmed in seedlings using PCR amplification with the following primers: 5'AAGGCTTCTGATACGGACAAG3' (forward) and 5'TCTTACGGCTTCCATCACTTC3' (reverse).

\section{RNA Extraction and Quantification}

Total RNA was extracted from $200 \mathrm{mg}$ fruit tissue with TRI Reagent RNA isolation reagent (Sigma-Aldrich), according to the manufacturer's protocol. For CDNA preparation, reverse transcription was done with the iScript ${ }^{\mathrm{TM}}$ gDNA Clear cDNA Synthesis Kit $\# 172-5,035$ (Bio-Rad). Rapid amplification of $5^{\prime}$ cDNA end (5'-RACE) analyses to determine the $5^{\prime}$ end of the transcripts of PSY1 were carried out with SMART ${ }^{\otimes}$ RACE $5^{\prime} / 3^{\prime}$ Kit from Clontech Laboratories Inc. (Mountain view, Ca, United States) according to the manufacturer's protocol. The reverse primer was 5'-TCCATACGCATTCCTTCAATC-3' (exon \#7).

To measure transcript levels of PSY1 and PSY2, the cDNA was amplified using ProFlex PCR System (Applied Biosystems by Thermo Fisher Scientific) in a quantitative PCR protocol using the Applied Biosystems ${ }^{\mathrm{TM}}$ Fast SYBR ${ }^{\mathrm{TM}}$ Green Master Mix on a StepOnePlus ${ }^{\mathrm{TM}}$ Real-Time PCR System (Applied Biosystems). Cycling conditions were $95^{\circ} \mathrm{C}$ for $20 \mathrm{~s}$, followed by 40 cycles of $95^{\circ} \mathrm{C}$ for $3 \mathrm{~s}, 60^{\circ} \mathrm{C}$ for $30 \mathrm{~s}$ and fluorescence acquisition at $60^{\circ} \mathrm{C}$. For each gene, the relative mRNA level was determined in three biological replicates. The primers used for the RT-PCR amplifications were $5^{\prime}$-AACTTGTTGATGGCCCAAAC- $3^{\prime}$ (forward) and $5^{\prime}$-CTGTATCGGACAAAGCACCA-3' ${ }^{\prime}$ (reverse), for PSY1 
(Solyc03g031860); 5'-AGTTCTGCTAGTAGATGGCC-3' (forward) and $5^{\prime}$-GGGCACTAGAGATCTTGCAT-3' (reverse) for PSY2 (Solyc02g081330); and 5'-AACAGTTGGCCTAATGAGTGTGC-3' for PSY3 (Solyc01g005940) The ACTIN gene (Solyc11g005330) served as a control for normalization, using the primers 5'-TTGCTGACCGTATGAGCAAG-3' (forward) and 5'-GGACAATGGATGGACCAGAC-3' (reverse) that differentiate between genomic DNA and cDNA sequences.

\section{Functional Assay of PSY1 Transcripts}

To investigate the enzymatic activity of the different PSY1 variants from $r^{2997}$, the complete cDNA of this gene was obtained from RNA isolated from pulp of fresh fruit of $r^{2997}$ followed by RT-PCR using the primers $5^{\prime}$-AGCCACTAGTTGGCTTGTTGAGTGAAGCATAT-3' (forward) and 5'-GTCGCTCGAGCTCATGCTTTATCTTTGAAGAGAGG- $3^{\prime}$ (reverse). The PCR products were cloned into the plasmid pBluescript $\mathrm{SK}^{+}$between the SpeI and XhoI restriction sites, and the plasmids were transfected into Escherichia coli cells of the strain XL1Blue. Sequencing of different bacterial colonies obtained from this cloning revealed two variants that can produce possible functional open reading frames of PSY1. One of these variants resulted from skipping over exon \#4 of PSY1 while the other from skipping over exon \#2 and exon \#4 of this gene. Thus, these two new plasmids were termed pPSY1V1 and pPSY1V2, respectively. As a control, the full-length transcript was amplified from wild-type tomato fruit and cloned into the plasmid pBluescript $\mathrm{SK}^{+}$between the SpeI and XhoI sites, generating the pfull_PSY1 vector. The inserts were sequenced to identify possible PCR-derived mutations.

The plasmid pACCRT-EIB carries the Pantoea agglomerans genes Idi, crtE, crtI, and crtB that produce lycopene when expressed in E. coli (Cunningham and Gantt 2007). The crtB gene, which encodes phytoene synthase, was knocked out pACCRT-EIB through site-directed mutagenesis using the protocol of QuikChange ${ }^{\circledR}$ Site-Directed Mutagenesis Kit of Stratagene (La Jolla, CA) with the KAPA HiFi HotStart ReadyMix enzyme with the primers $5^{\prime}$-TCAGGAAGTGGCTATGCTCATGATATCGCCCC-3' (forward) and 5'-GGGGCGATATCATGAGCATAGCCACTTCCTGA-3' (reverse). The new plasmid was called pACCRT-EI. Plasmids pPSY1V1, pPSY1V2, and the full-length PSY1 cDNA plasmid pfull_PSY1, were co-transfected with pACCRT-EI to E. coli strain XL1-Blue grown on Luria-Bertani (LB) medium containing the antibiotics ampicillin and chloramphenicol. To enhance the expression of these genes, $24 \mathrm{mg} / \mathrm{l}$ of Isopropyl 1 -thio- $\beta$-Dgalactopyranoside (IPTG) was added to the LB medium. $E$. coli cells were grown overnight at $37^{\circ} \mathrm{C}$ on LB agar plates followed by 5 days at room temperature for pigment accumulation.

\section{Pigment Extraction and Analysis}

Fresh samples of fruit were collected from three biological replicates. Fruit pigments were extracted from 200 to $250 \mathrm{mg}$ of fresh pericarp tissue at the "breaker" and "ripe" (breaker plus 7 days) stages. The tissue was ground in $1 \mathrm{ml}$ of $1: 1$ water chloroform mixture. The chloroform phase was separated by centrifugation and dried under a stream of $\mathrm{N}_{2}$. The dried carotenoid extracts were dissolved in $300 \mu \mathrm{l}$ acetone. Carotenoids were separated by high-performance liquid chromatography analysis as previously described (Karniel et al., 2020).

\section{Chemical Inhibition of Phytoene Desaturase and Lycopene Cyclase}

Inhibition of phytoene desaturase (PDS) was achieved with the inhibitor norflurazon (4-chloro-5-(methylamino)-2-[3(trifluoromethyl)phenyl]pyridazin-3-one), or its commercial formulation herbicide Zorial (Sandmann et al., 1989). For inhibition in fruits, a volume of $500-700 \mu \mathrm{l}$ of $100 \mu \mathrm{M}$ Zorial was injected into mature green fruits and analyzed at the ripe stage. Inhibition of PDS in fruit pericarp ex-planta was carried out with $100 \mu \mathrm{l}$ of norflurazon/Zorial externally laid on pericarp disks taken from fruits at the mature green stage, as previously described (Pankratov et al., 2016). Inhibition of the enzymes LCY-B and CYC-B was performed with the inhibitor 2-(4-Chlorophenylthio)-triethylamine hydrochloride (CPTA). One milliliter of CPTA at a concentration of $100 \mu \mathrm{M}$ was injected into mature green fruits with a $0.4 \mathrm{~mm}$ X $20 \mathrm{~mm}$ needle. Fruits with yellow and red sectors were observed at the ripe stage 4-7 days following the injection. The different pericarp sectors were dissected for carotenoid and transcript measurements.

\section{Silencing of the Gene PSY2}

A VIGS experiment was established as previously described (Fantini et al., 2013). The pTRV2_DR plasmid was kindly supplied by Dr. Giovanni Giuliano, ENEA, Italy. A PSY2-specific silencing sequence was amplified with the primers 5'-GGGGACAAGTTT GT ACAAAAAAGCAGGCTGACGTTGCCCATTGCTTATGC- ${ }^{\prime}$ (forward) and 5'-GGGGACCACTTTGTACAAGAAAGCTGGG TACTCAAATGAAGTCAATTATC- $3^{\prime}$ and cloned in the pTRV2_DR using the Gateway BP Clonase II enzyme mix and Gateway LR Clonase II enzyme according to the manufacturer's protocol.

\section{Statistical Analysis}

Statistical analysis of the parameters measured in field trials was performed using JMP 15 software (SAS Institute). Mean values of the parameters of the different tested genotypes were compared using the "Fit Y by X" function and "Compare all pairs" (Tukey-Kramer).

\section{RESULTS}

\section{Molecular Characterization of the Mutation Yellow-flesh $r^{2997}$}

Previous studies suggested that the locus yellow flesh $r^{2997}$ is genetically linked to the PSY1 gene in chromosome \#3. However, the molecular basis of the mutation has remained unknown (Kachanovsky et al., 2012). To find the $r^{2997}$ mutation, a mapping population of $310 \mathrm{~F} 2$ plants was created from a cross between 
the homozygous $r^{2997}$ tomato line LA2997 in the Rutgers variety genetic background and the red-fruited wild species $S$. pimpinellifolium. The mapping relied initially on two polymorphic markers between S. pimpinellifolium and S. lycopersicum, named INDEL1 and INDEL2, found in the genomic sequence spanning $\sim 1600 \mathrm{~kb}$ around the PSY1 gene in chromosome \#3 (Supplementary Table S1; Supplementary Figure S1). Sixty recombinant plants between these markers were phenotyped for fruit color and were further screened with additional fourteen PCR markers (Supplementary Table S1). Due to the recessive nature of the mutation, heterozygous red-fruited plants were self-pollinated, and fruit color was checked in the F3 generation (Supplementary Figure S1A). The association between fruit phenotypes and the DNA marker results enabled us to localize the $r^{2997}$ mutation within $24 \mathrm{~kb}$ between markers PSY1-3' and 8,587 that spanned the whole PSY1 gene (Supplementary Figure S1B). Using PCR amplification with primers located in this region, we have amplified an insertion of $4,867 \mathrm{bp}$ in exon \#4 of the PSY1 gene in yellow flesh allele $r^{2997}$. The nucleotide sequence of the insertion (Supplementary Figure S2) is identical to a known Ty1-copia-like retrotransposon of the Rider family (GenBank: EU195798.2; Cheng et al., 2009), which contains 397 nucleotide long terminal direct repeats (LTR) at both borders, an open reading frame encoding a Ty1-copiatype polyprotein, and a primer-binding site (PBS) and polypurine tract site (PPT). Interestingly, the $5^{\prime}$ end of the retrotransposon sequence is identical to the previously published sequence of GTOM5, an abortive mRNA transcript of PSY1 from the mutant yellow flesh $r$ in the tomato variety Ailsa Craig (Fray and Grierson, 1993a).

\section{Effects of the Retrotransposon on the Expression of PSY1}

A rapid amplification of $5^{\prime}$ cDNA ends (5'-RACE) analysis was carried out to determine the transcription initiation site of PSY1 in the wild-type tomato variety. The results showed that 81 percent of the transcripts started in the first exon and the others in exon \#4 (Supplementary Figure S3). In the fruits of mutant $r^{2997}$, all the PSY1 transcripts were initiated in exon \#1 (Figure 2). The primary one was a fusion of exon \#4 with the retrotransposon sequence (transcript I in Figure 2). This fused transcript creates an early stop codon, similar to the one described in GTOM5 from yellow flesh $r$ in the Ailsa Craig variety (Fray and Grierson, 1993a). Therefore, we conclude that $r^{2997}$ in LA2997 and $r$ in Ailsa Craig are essentially the same yellow flesh allele derived from the ancestral yellow-fruited tomato line. In addition to the most abundant abortive PSY1 transcript, fruits of $r^{2997}$ produce additional transcripts resulting from alternative splicing events (Figure 2). These transcript variants lack the retrotransposon-containing exon \#4 and include exons 5-9, which encode the C-terminus of the PSY1 protein where the catalytic domain is located (Cao et al., 2019). The functionality of the alternatively spliced variants was tested in E. coli cells. For this purpose, the cDNA of variants II and III (Figure 2), which contain the coding sequence of exons 5-9, and the normal cDNA sequence of exons 4-9 were cloned in the plasmid pBluescript $\mathrm{SK}^{+}$. These plasmids were transfected into E. coli cells carrying plasmid pACCRT-EI, which encodes the bacterial genes CrtE and CrtI for geranylgeranyl diphosphate synthase and phytoene desaturase, respectively. In the presence of phytoene, these enzymes can synthesize lycopene. As expected, the E. coli cells that expressed the full-length PSY1 were red due to lycopene accumulation. In contrast, PSY1 variants lacking exon \#4 are not translated into enzymatically active proteins, as the alternatively spliced PSY1 variants II and III gave rise to colorless bacteria that did not produce carotenoids (Supplementary Figure S4). These results show that PSY1 variants lacking exon \#4 are enzymatically inactive, as is evident in fruits of the mutant yellow flesh $r^{2997}$.

\section{Epistasis in the Carotenoid Biosynthesis Pathway in Tomato Fruit}

The epistasis phenomenon found in the double mutant yellow flesh $r^{2997}$ /tangerine (Kachanovsky et al., 2012) was further investigated in various allele combinations. Fruits of the introgression line IL3-2, which carries the PSY1 gene from $S$. pennellii in the variety M82, are yellow and lack carotenoids due to a substantial reduction in PSY1 expression compared to its isogenic cultivated line M82 (Liu et al., 2003; Joung et al., 2009). Therefore, the PSY1 gene from S. pennellii in the genetic background of the cultivated tomato can be considered as a yellow flesh allele, $r^{\text {sp }}$. The IL3-2 line was crossed with the isogenic tangerine $t^{3406}$ and zeta $z^{2803}$ mutants, which are impaired in the genes CRTISO and ZISO, respectively, to produce in $\mathrm{F} 2$ generation double mutants IL3-2 $r^{\mathrm{sp}} / t^{3406}$ and IL3-2 $r^{\mathrm{sp}} / z^{2803}$. The genotypes of these mutants were confirmed with DNA markers. In agreement with previous observations of the yellow flesh allele $r^{2997}$, fruit of the double mutant IL3-2 $r^{\mathrm{sp}} / t^{3406}$ accumulated carotenes, though at a lower level than the wild type, mainly in cisconfigurations (Table 1). These results confirm that the epistasis of tangerine over yellow flesh is a general phenomenon and is not confined to a specific $r$ allele. Another yellow flesh allele, $r^{3756}$, which was isolated by mutagenesis in the tomato variety M82, contains an early stop codon in exon \#4 of the PSY1 gene (Kachanovsky et al., 2012). Fruits of the double mutant $r^{3756} t^{3002}$ were orange due to the accumulation of low levels of carotenes (Table $\mathbf{1}$ and Supplementary Figure S5). These results indicate that tangerine is also epistatic over the null yellow flesh allele $r^{3756}$. As previously reported (Kachanovsky et al., 2012), the epistasis phenomenon is linked to the CRTISO impairment but not to the ZISO function loss because fruits of the double mutant IL3-2 $r^{\mathrm{sp}} / z^{2803}$ were yellow and contained only trace amounts of carotenoids (Table $\mathbf{1}$ ).

Previous results have shown that the mutation tangerine leads to a substantial increase in the transcription of PSY1 in $r^{2997}$ fruit compared to the single mutant $r^{2997}$ (Kachanovsky et al., 2012). To analyze the effect of tangerine on the expression of PSY1, we established several new qRT-PCR 


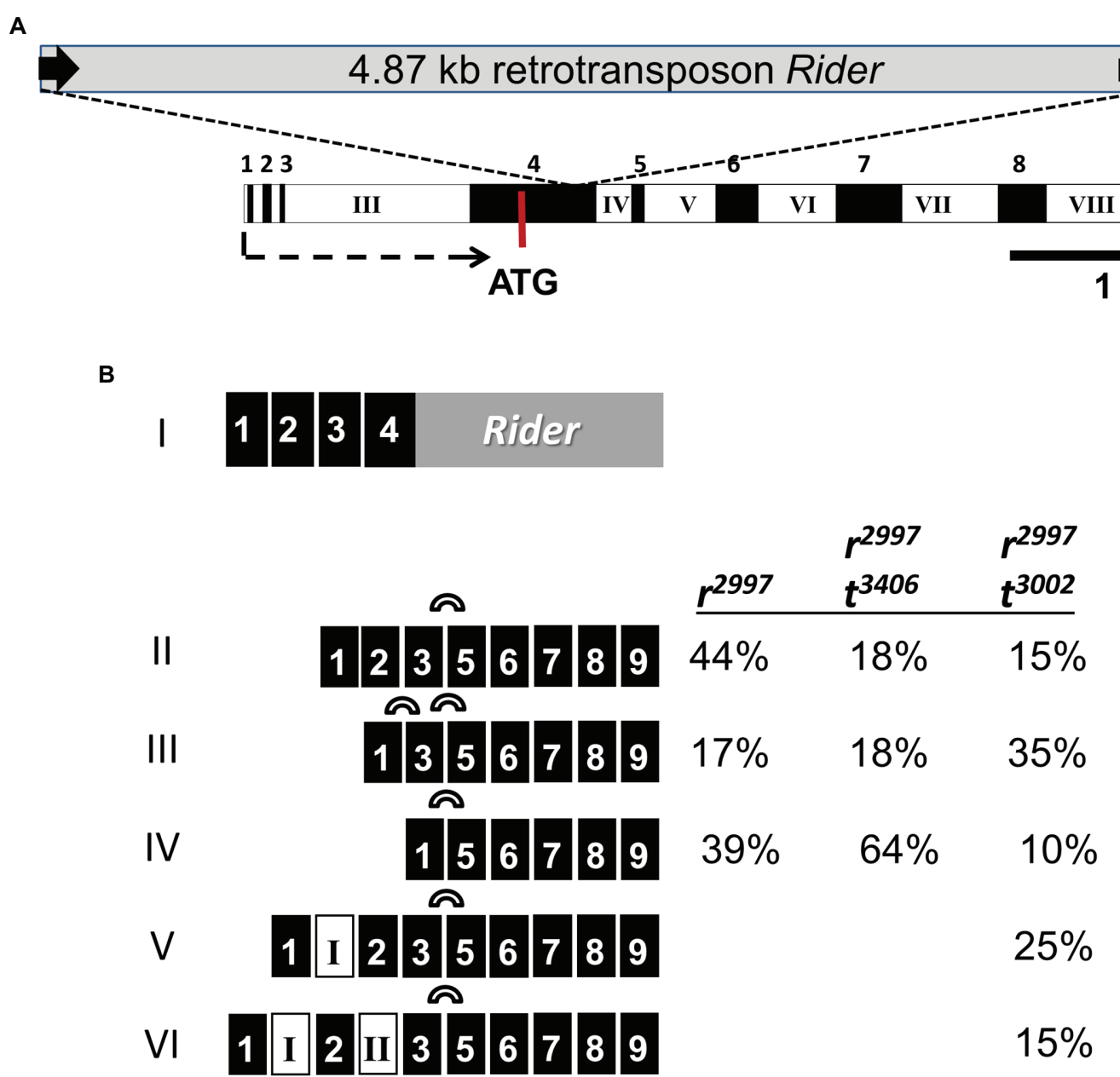

FIGURE 2 | The PSY1 gene in the mutant $r^{2997}$ and its transcripts. (A) Genomic structure of PSY1 with nine exons (filled boxes) and eight introns. The Rider retrotransposon is located in exon \#4. Arrow indicates transcription initiation. (B) PSY1 transcript variants detected in fruits of mutant $r^{2997}$ and double mutants $r^{2297 / t a n g e r i n e . ~ T h e ~ p r o p o r t i o n s ~ o f ~ t h e ~ v a r i o u s ~ t r a n s c r i p t s ~ w e r e ~ c a l c u l a t e d ~ f r o m ~ t h e ~ t o t a l ~ t r a n s c r i p t s ~ t h a t ~ c o n t a i n e d ~ e x o n s ~ 5-9 . ~}$

TABLE 1 | Carotenoid composition in ripe fruit of various tomato lines ( $\left.\mu \mathrm{g} \mathrm{g}^{-1} \mathrm{FW}\right)$.

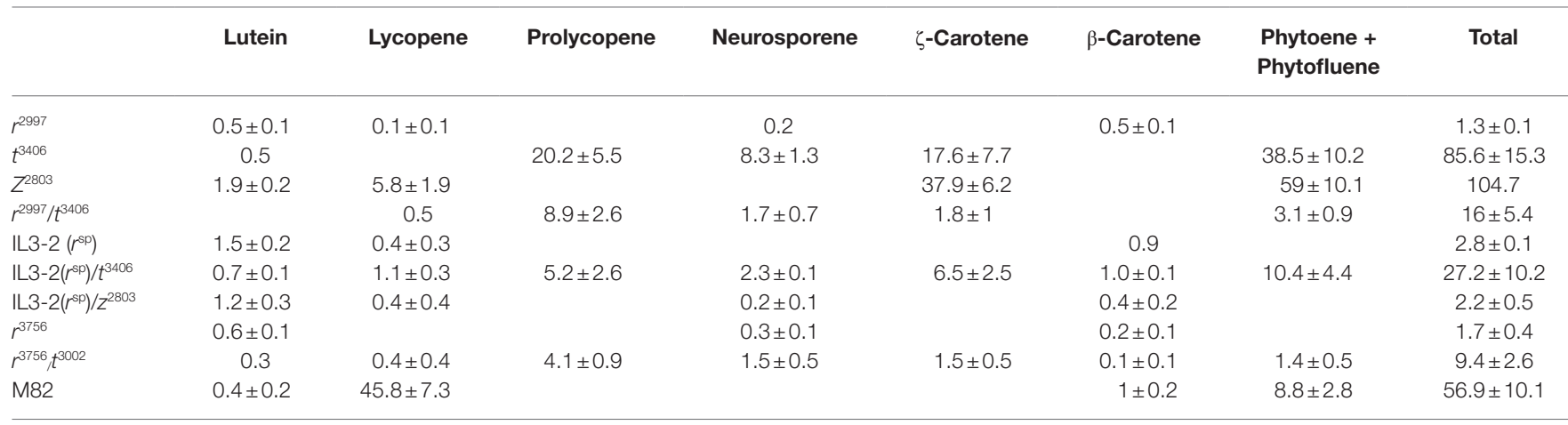

$r^{2997}$ and $r^{3756}$ are yellow flesh alleles; $t^{3406}$ and $t^{3002}$ are tangerine alleles; $z^{2803}$ is a null allele of zeta. M82 represents the wild type.

protocols with primers for exon \#6 to measure the mRNA level of PSY1. The results confirmed that the transcript levels of PSY1 in the double mutant tangerine/ $r^{2997}$ appeared to be higher than in $r^{2997}$, however, to a lower extent than previously reported (Figure $3 \mathbf{A}$ ). The increase of PSY1 transcript in IL3-2( $\left.r^{\mathrm{sp}}\right) / t^{3406}$ compared with IL3-2( $\left.r^{\mathrm{sp}}\right)$ was relatively modest, but the data were not significant in this case (Figure 3B). Expression of PSY2 in fruits of the yellow flesh/tangerine double mutants was lower than in the yellow flesh alleles $r^{2997}, r^{3756}$, and IL3-2 ( $r^{\mathrm{sp}}$; Figure 3C). In compliance 


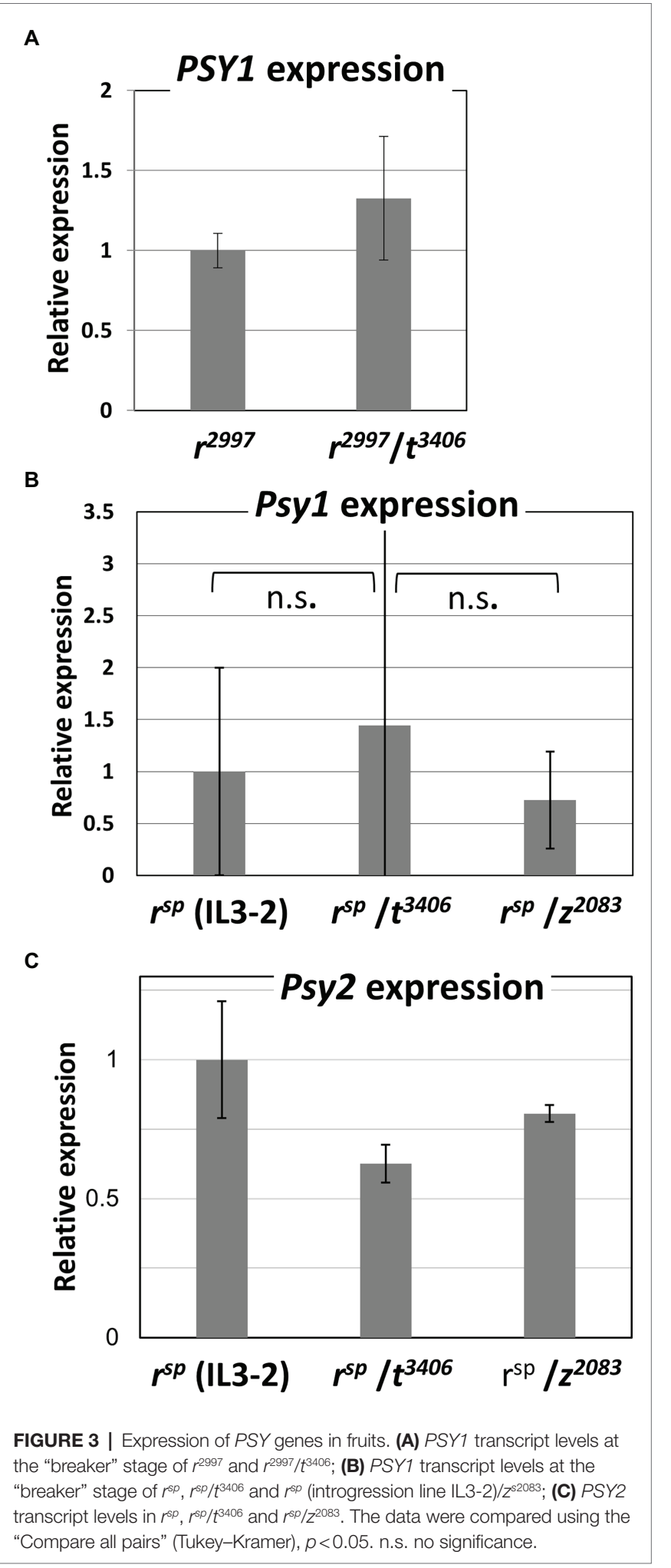

with the PSY 3 expression pattern in tomato, ${ }^{1}$ the root-specific SIPSY3 (Solyc01g005940) could not be detected with qRT-PCR in fruits of any of these lines.

${ }^{1}$ https://tea.solgenomics.net/expression_viewer/output

\section{Activation of Carotenoid Biosynthesis in Yellow Flesh Fruits by Inhibition of Carotenoid Biosynthesis Downstream of Phytoene}

Since tangerine obstructs carotenoid biosynthesis at the isomerization of cis-lycopene, we investigated the effects on phytoene synthesis of other pathway inhibitors. Norflurazon (Zorial) is a specific inhibitor of the plant enzyme phytoene desaturase (PDS; Sandmann et al., 1989). To test the effect of norflurazon, its commercial formula Zorial was injected into mature green fruits of the yellow flesh mutant $r^{2997}$. After ripening, diffused red sectors appeared in the treated fruit due to the accumulation of carotenoids (Figure 4A). A similar experiment was done in ex-planta fruit tissues. Disks of pericarp taken from mature green fruits of yellow flesh $r^{2997}$ and the wild-type variety Rutgers were incubated in vitro and treated with Zorial. The Rutgers fruit disks appeared yellow to orange, as opposed to red in the untreated disks. The colors of the mutants' disks were not changed compared to untreated control. However, carotenoid composition in the disks indicated that PDS inhibition induced phytoene synthesis in both yellow flesh fruit mutants ex-planta (Figure 4B).

The effect of inhibition of carotenoid biosynthesis downstream to lycopene was investigated in yellow flesh mutants treated with the lycopene $\beta$-cyclase inhibitor 2-(4-Chlorophenylthio)triethylamine hydrochloride (CPTA; Sandmann et al., 1989; Cunningham et al., 1993). CPTA was injected to mature green fruits of mutants $r^{2997}, r^{3756,}$ and IL3-2 $\left(r^{\mathrm{SP}}\right)$. In all mutants, the lycopene cyclase inhibition altered the fruit color in distinct sectors, which appeared red due to lycopene synthesis (Figure 5A, Table 2). However, the carotenoid composition varied among the different yellow flesh mutants. While in $r^{2997}$, CPTA induced the accumulation of cis-carotenes, which led to red color appearance, in $r^{3756}$ and IL3-2 $\left(r^{\mathrm{sp}}\right)$ it caused the accumulation of mainly lycopene (Table 2). The expression of PSY1 did not significantly change in the CPTA-treated sectors compared to the non-treated sectors. However, the expression level of PSY2 was doubled (Figures 5B,C).

To investigate the potential involvement of PSY2 in the restoration of phytoene production in the double mutants of tangerine and yellow flesh, expression of the gene PSY2 was inhibited by a transient VIGS. To this end, we created a tomato line that combined the mutations yellow flesh $r^{2997}$ and tangerine $t^{3002}$ with the transgenic line overexpressing the transcription factors Delila (Del) and Rosea1 (Ros1; DR), as visual reporters for silencing in tomato fruit (Butelli et al., 2008; Orzaez et al., 2009). The quadruple mutant line was named $D R / r^{2997} / t^{3002}$. A TRV-based silencing vector was constructed to silence both PSY2 and the transgenes Del and Ros1. The Si-RNA sequence was designed to specifically silence PSY2, but not PSY1 or PSY3 (Materials and Methods). The silencing TRV vectors were injected to green fruits of the lines $D R / r^{2997} / t^{3002}$ and $D R$ as a control. The silenced sectors were identified in ripe fruit by eliminating anthocyanins. In the $D R / r^{2997} / t^{3002}$ fruit they appeared yellow and in $D R$ they were red (Figure 6A). Carotenoid analysis indicated that non-silenced tissues of $D R / r^{2997} / t^{3002}$ 

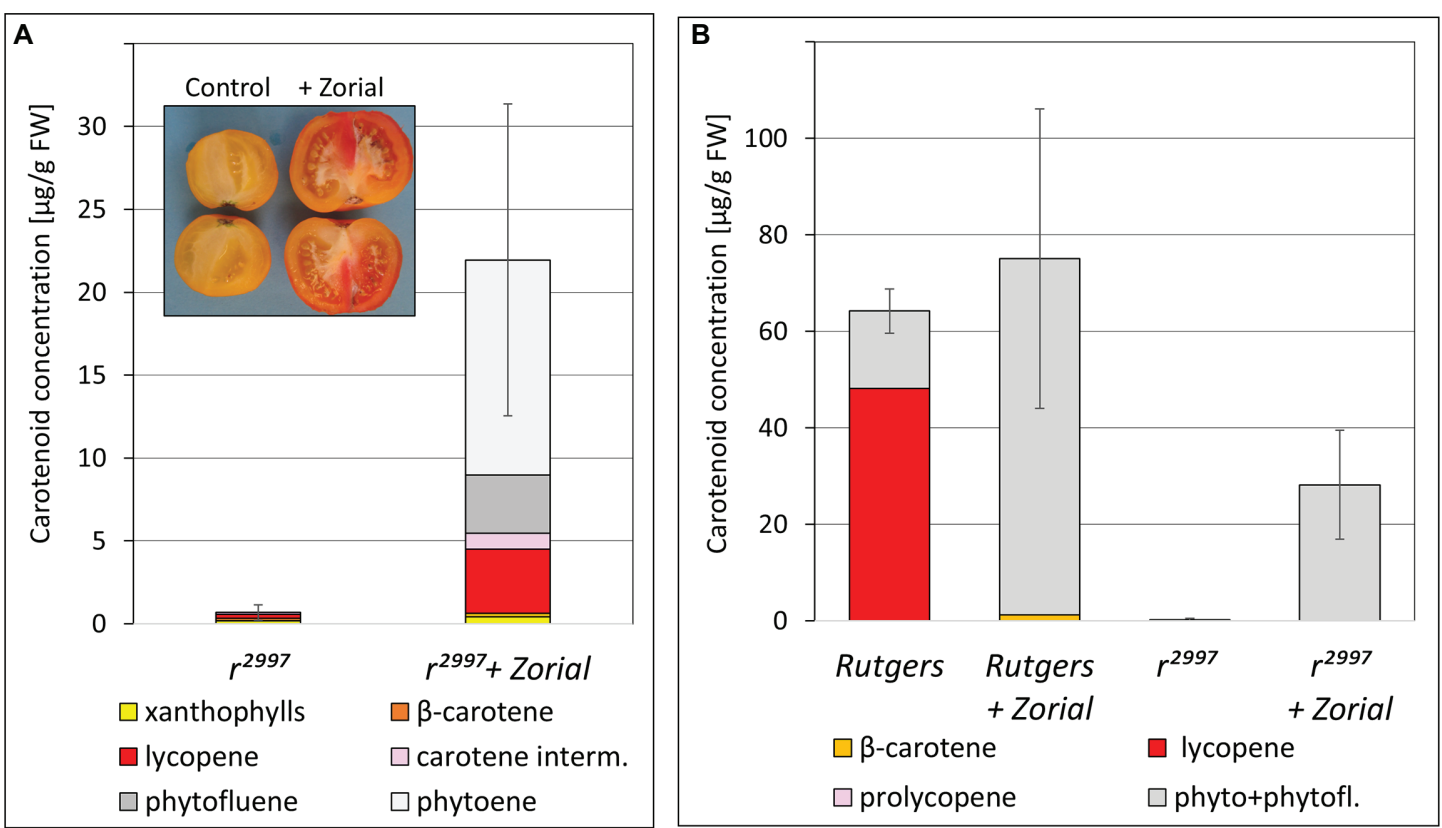

FIGURE 4 | Effects of norflurazon (Zorial) on pigment accumulation in the fruit of yellow flesh $r^{2997}$ (Rutgers variety background). (A) Carotenoid composition in fruits after Zorial injection. (B) Carotenoid composition in pericarp explants from Rutgers (wild type) and mutant $r^{2997}$ treated with Zorial (Z).
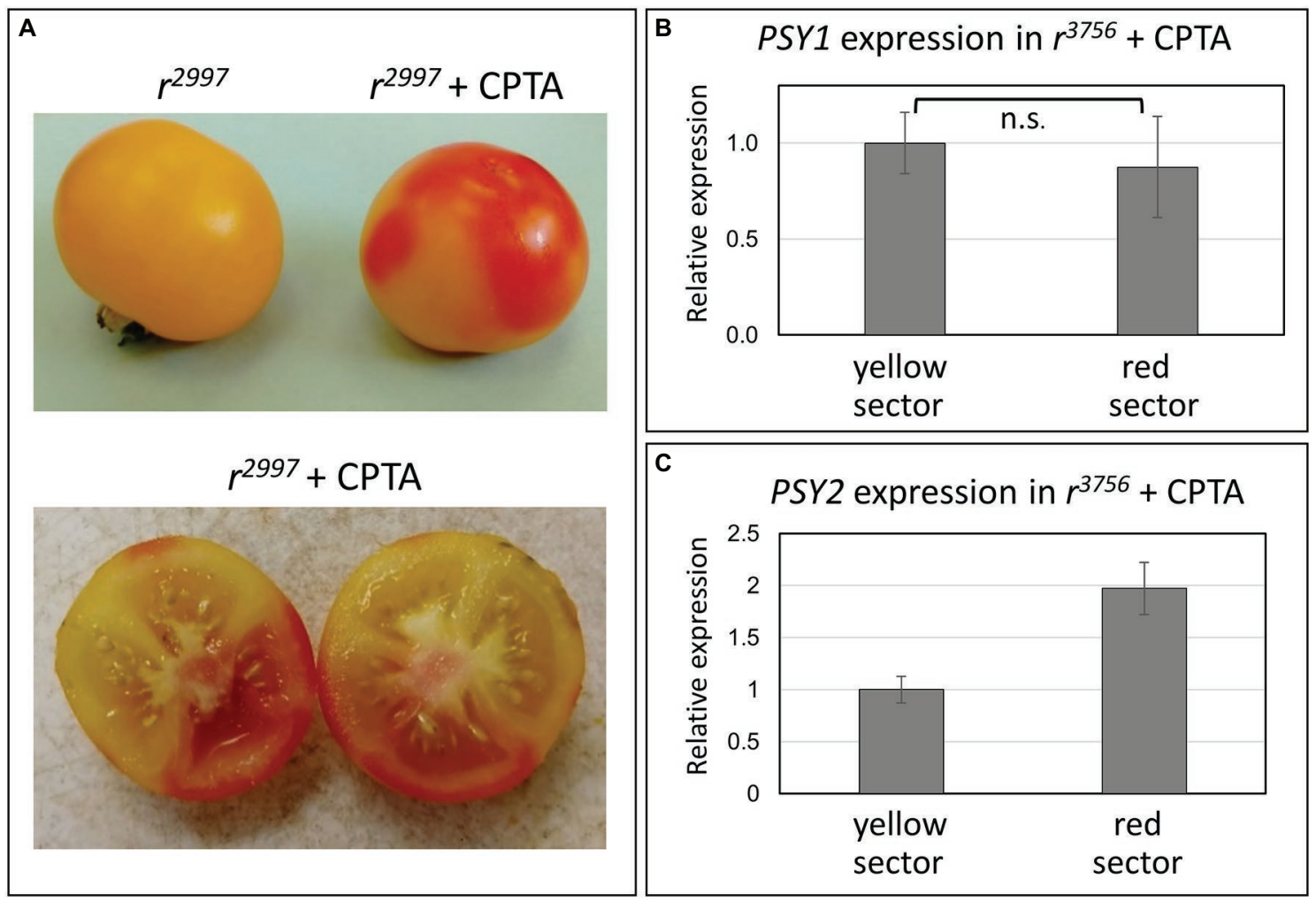

FIGURE 5 | Effects of CPTA on pigment accumulation in tomato fruit. (A) Fruits of the yellow flesh $r^{2997}$ mutant before and after CPTA treatment. (B) Expression of PSY1 in the yellow and red fruit sectors. (C) Expression of PSY2 in the yellow and red fruit sectors. Different tested parameters were compared using the "Compare all pairs" (Tukey-Kramer), $p<0.05$. n.s. no significance. 
TABLE 2 | Carotenoid composition in fruit sectors.

\begin{tabular}{|c|c|c|c|c|c|c|c|c|}
\hline & Lutein & Lycopene & Prolycopene & Neurosporene & $\zeta$-Carotene & $\beta$-Carotene & $\begin{array}{l}\text { Phytoene + } \\
\text { Phytofluene }\end{array}$ & Total \\
\hline CPTA/ $r^{\text {sp }}$ (IL3-2) yellow sector & 1 & 0.2 & & 0.1 & & 0.9 & & 2.2 \\
\hline CPTA $r^{\text {sp }}$ (IL3-2) red sector & $1.3 \pm 0.2$ & $68.6 \pm 16.9$ & & & & & $3.7 \pm 1.3$ & $73.6 \pm 18.4$ \\
\hline CPTA $r^{3756}$ yellow sector & $0.7 \pm 0.1$ & & & $0.4 \pm 0.1$ & & 0.3 & & $1.4 \pm 0.2$ \\
\hline CPTA $/ r^{3756}$ red sector & $0.6 \pm 0.2$ & $21.6 \pm 2.4$ & & & & & & $22.2 \pm 2.5$ \\
\hline CPTA $/ r^{2997}$ yellow sector & $1.6 \pm 0.3$ & $1.1 \pm 0.7$ & & & $2.5 \pm 1$ & $0.8 \pm 0.3$ & $8.8 \pm 3$ & $14.8 \pm 5.1$ \\
\hline CPTA $r^{2997}$ red sector & $0.4 \pm 0.1$ & $0.8 \pm 0.2$ & $3.2 \pm 0.4$ & $2.6 \pm 0.7$ & $13.9 \pm 1.4$ & $1.2 \pm 0.2$ & $21.8 \pm 2.6$ & $46.4 \pm 4.9$ \\
\hline
\end{tabular}

Yellow and red fruit sectors following CPTA treatment of the yellow flesh alleles $I L 3-2, r^{3756}$ and $r^{2997}$ were analyzed $\left(\mu g g^{-1} \mathrm{FW}\right)$.

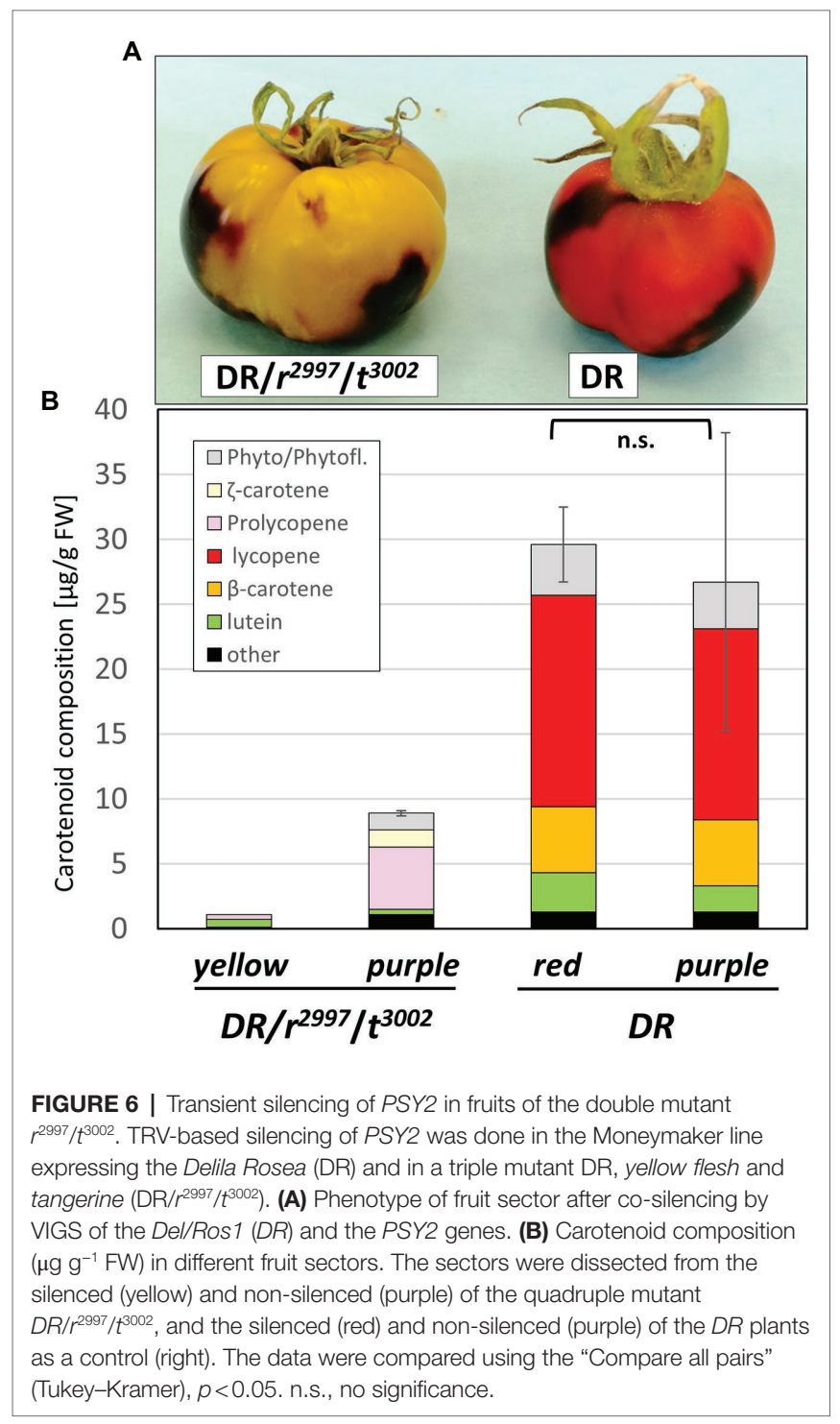

accumulated cis-carotenoids typical to the $r^{2997} / t^{3002}$ double mutant, whereas carotenoid synthesis in the PSY2-silenced sectors was nearly abolished (Figure 6B; Supplementary Table S2). Similar silencing of PSY2 in the Del/Ros1 Moneymaker line did not change the carotenoid composition (Figure 6; Supplementary Table S2). Quantification of mRNA confirmed specific and efficient silencing of PSY2 in the silenced sectors, while the expression of PSY1 was unchanged (Figure 7). The elimination of carotenoid synthesis by PSY2 silencing in the $D R / r^{2997} / t^{3002}$ line confirms that carotenoid biosynthesis recovery in the double mutant $r^{2997} / t^{3002}$ depends on PSY2 activity.

\section{DISCUSSION}

\section{The Origin and Molecular Basis of the Yellow-flesh, $r^{2997}$}

Several yellow flesh mutants in the locus $r$ have been identified in tomatoes (Tomato Genetics Resource Cente). ${ }^{2}$ The allele $r^{2997}$ (LA2997), which is described as a spontaneous mutation in the variety Rutgers, is considered the oldest allele (Chetelat, 2002) that was originated from the yellow variety brought to Europe in the 16th Century (McCue, 1952; Bergougnoux, 2014) and genetically characterized in the early 20th century (Price and Drinkard, 1909; Gilbert, 1912; Jenkins, 1948). We have confirmed that the mutation in $r^{2997}$ is caused by an insertion of a copia-type retrotransposon Rider in the coding region of PSY1. The sequence of the insertion in exon \#4 (Supplementary Figure S2) indicates a full-length Rider retrotransposon (Jiang et al., 2012). Previously, we missed identifying the mutation in $r^{2997}$ while using genomic DNA sequencing based on PCR amplification (Kachanovsky et al., 2012). The existence of a complete retrotransposon bordered by identical long terminal repeats (LTR) often forms a stable stem-loop secondary structure. Most Taq-polymerases used in PCR amplifications skip stem-loop structures due to the replication slippage mechanism observed in the presence of direct repeats in the DNA (Viguera et al., 2001). Unlike previous analyses, here we used an engineered Taq polymerase, KAPA2G Fast, with higher processivity and speed under conditions that enabled the amplification of the full-length retrotransposon. LTR retrotransposons comprise more than $60 \%$ of the tomato genome. Most of them exist for millions of years in the exact chromosomal location (Tam et al., 2007; Cheng et al., 2009; Du et al., 2010; Jiang et al., 2012). Therefore, it is reasonable to assume that the retrotransposon mutation in $r^{2997}$ is ancient and that it has prevailed throughout the tomato's history since it was brought to Europe from America. The sequence of the retrotransposon LTR was previously detected in the GTOM5 mRNA from a yellow flesh mutation in the variety Ailsa Craig

${ }^{2}$ https://tgrc.ucdavis.edu/Data/Acc/GenDetail.aspx?Gene=r 

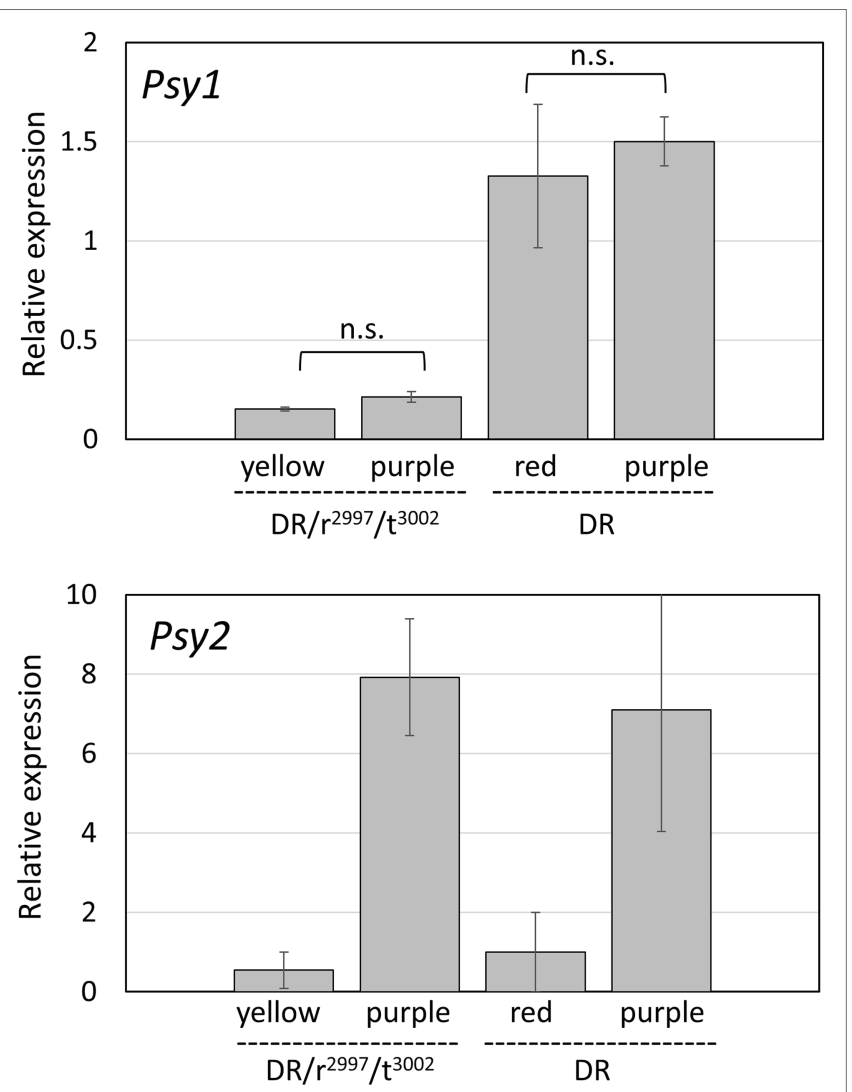

FIGURE 7 | Transcript levels of PSY1 and PSY2 in silenced and nonsilenced sectors dissected from VIGS-treated fruits of the $D R / r^{2997} / t^{3002}$ and $D R$ (control) plants. The data were compared using the "Compare all pairs" (Tukey-Kramer), $p<0.05$. n.s. no significance.

(NCBI Reference Sequence: X67143.1; Fray and Grierson, 1993a). Fray and Grierson (1993a) have predicted that this sequence belonged to a transposable element based on Southern blot hybridizations. According to the sequence of PSY1 in yellow flesh $r^{2997}$ (Supplementary Figure S2), it is evident that this is the same $r$ allele described before in the Ailsa Craig variety (Fray and Grierson, 1993a). The phenotype of yellow flesh $r^{2997}$ has been ascribed to the lack of PSY1 transcription (Kachanovsky et al., 2012). This notion was supported by the fact that functional PSY1 genes introgressed to S. lycopersicum from green-fruited wild tomato species exhibit yellow flesh phenotypes, as demonstrated by the allele $r^{\text {sp }}$ (Table 1). The existence of a $4.8 \mathrm{~kb}$ Rider retrotransposon in the first coding exon of PSY1 explains the drastic reduction of mRNA measured by RT-PCR analysis based on the amplification of cDNA sequences downstream of exon \#4.

\section{Reactivation of PSY2 in Ripening Tomato Fruit}

The epistasis of the mutation tangerine over yellow flesh $r^{2997}$ was attributed to increased transcription of PSY1 in the double mutant $r^{2997} / t^{3002}$ (Kachanovsky et al., 2012). Loss-of-function mutations in the gene CRTISO were found to increase PSY1 expression and enhance total carotenoids in fruits of tangerine tomato (Isaacson et al., 2002; Isaacson, 2005) and the yofi in melon (Cucumis melo; Galpaz et al., 2013). In both cases, the accumulation of cis-carotene intermediates could play a role in regulating gene expression (reviewed in: Cazzonelli et al., 2020; Escobar-Tovar et al., 2020). Measuring mRNA of PSY1 in fruits of $r^{2997} / t^{3406}$ by RT-PCR amplification of exon \#6 sequence showed a slight elevation compared to yellow flesh $r^{2997}$ (Figure 3). However, this small increase in Psy1 transcript cannot explain the restoration of phytoene synthase activity in the double mutant. This result differs from previous measurements in strain $r^{2997} / t^{3002}$ (Kachanovsky et al., 2012). The explanation for the discrepancy can be related to the different genetic backgrounds of $t^{3002}$ (Rutgers) and $t^{3406}$ (M82). Moreover, the Rider retrotransposon in exon \#4 is inserted after codon 107 of the PSY1 coding sequence. Consequently, the primary transcript of PSY1 in $r^{2997}$ consists of exons 1-3 and part of exon \#4 fused to the LTR sequence of the retrotransposon (Figure 2). It thus potentially encodes a chimeric non-functional polypeptide of 178 amino acids. Other rare transcript variants of PSY1 in $r^{2997}$ skip exon \#4, which encompasses the retrotransposon (Figure 2). However, a truncated PSY1 translated from exons 5-9 was inactive in the E. coli complementation assay (Supplementary Figure S4). These results indicate that the tomato mutant $r^{2997}$ lacks a functional PSY1 enzyme and, therefore, the gene expression level is irrelevant. PSY1-specific antibodies are not available, and consequently, it was not possible to obtain quantitative data on the aberrant PSY1 protein level. The phenomenon of tangerine epistasis has also been observed with allele $r^{3756}$ that carries a loss-of-function mutation in PSY1 (Table 1). This result challenges previous conclusions derived from the double mutant $r^{3756} / t^{3002}$ on the epistasis of tangerine over yellow flesh (Kachanovsky et al., 2012).

The results of the experiments described here (summarized in Figure 8) support an alternative option for recovering phytoene synthesis in the yellow flesh/tangerine double mutants by activating the leaf-specific phytoene synthase, PSY2. PSY1 is mainly expressed in the fruit, where its transcripts increase dramatically at the "breaker" ripening stage from practically undetectable levels at the mature green fruit. By contrast, PSY2 transcript level is quite similar in green and ripening fruit (Fraser et al., 1999, 2007; Fernandez-Pozo et al., 2017; Shinozaki et al., 2018; Tomato Expression Atlas). ${ }^{3}$ Moreover, in yellow flesh fruit, the PSY2 protein has been detected immunologically, and its enzymatic activity of phytoene synthesis has been demonstrated in vitro (Fraser et al., 1999). Nevertheless, PSY2 is not active in the fruits when PSY1 is impaired in yellow flesh mutants (Table 1; Fray and Grierson, 1993a; Fraser et al., 1999; Kachanovsky et al., 2012; Fantini et al., 2013; Chen et al., 2019; Zhao et al., 2020). The minuscule amount of carotenoids, mainly lutein and $\beta$-carotene, found in the fruits of yellow flesh, tangerine and zeta mutants, as well as in the norflurazon-treated wild-type fruits, are more likely residues from the chloroplasts prior to their transition to chromoplasts

${ }^{3}$ https://tea.solgenomics.net/ 


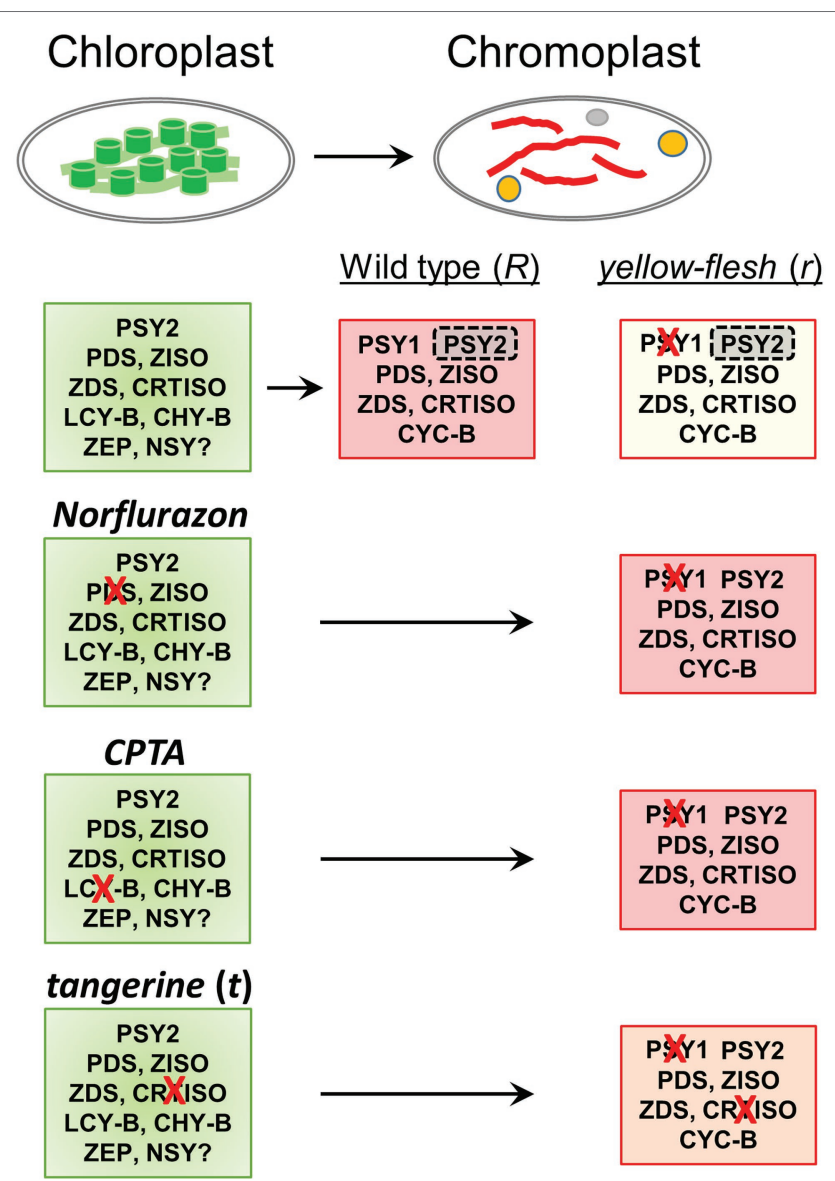

FIGURE 8 | Summary of the experimental scheme and results. Carotenoid biosynthesis enzymes in tomato chloroplasts and fruit chromoplasts are depicted in the relevant boxes (see Figure 1 for enzyme abbreviations). Phytoene is synthesized in the chloroplasts by PSY2 and in chromoplasts by PSY1. PSY1 is exclusively expressed in fruits and flowers while PSY2 is found in both chloroplasts and fruit chromoplasts. However, PSY2 is inactive in chromoplasts (shaded) and, therefore, carotenoid synthesis is blocked in the fruits of the mutant yellow flesh. Injection of norflurazon or CPTA into mature green fruit inhibits the enzymes PDS and LCY-B, respectively. Consequently, PSY2 remains active after the transition of chloroplasts to chromoplasts during fruit ripening and sustains carotenoid biosynthesis in the mutant yellow flesh. The mutation tangerine inhibits the enzyme CRTISO and causes the accumulation of tetra-cis-lycopene ("prolycopene"). This perturbation activates PSY2 in the double mutant tangerine/yellow flesh.

rather than a low basal activity of PSY2. An upregulation of PSY2 transcription in the yellow flesh/tangerine double mutants was ruled out (Figure 3). The unequivocal evidence that PSY2 sustains phytoene synthesis in $r^{2997} / t^{3002}$ fruits is the outcome of PSY2 silencing in these fruits. As seen in Figure 6, the lack of PSY2 abolished carotenoid biosynthesis in the double mutant. Why then PSY2 is not active in yellow flesh fruits, and what activates it in the genetic background of tangerine? It has been hypothesized that PSY2, which usually operates in chloroplasts, is not active in fruits due to failure to interact with other enzymes in the carotenogenic pathway in chromoplasts (Fraser et al., 1999). In such a case, tangerine could alter the carotenoid metabolon in chromoplasts in a way that enables
PSY2 to function. One possibility is the localization of the enzyme in the plastids. The location of the biosynthesis enzymes, including PSY, is associated with the accumulation and sequestration of carotenoids (reviewed in: Li et al., 2016). A change in the PSY2 compartment within the plastids could enable its accessibility to the carotenoid metabolon in the chromoplasts. It was reported that PSY isozymes from various plants differ in their plastid sub-organellar localization, such as specific membranes or plastoglobuli (Shumskaya et al., 2012; Ampomah-Dwamena et al., 2015). The mutation tangerine eliminates carotenoids downstream to lycopene and causes an abnormal accumulation of cis-carotenes, mainly tetra-cis-lycopene (prolycopene). These changes in carotenoid constituent could modify the plastidial membrane organization, as seen in the Arabidopsis $c c r$ mutants, which alter the membranous structures in etioplasts (Park et al., 2002). In this context, it must be emphasized that the effect of the tangerine mutation is already manifested in mature green fruit where significant amounts of cis-carotenoids accumulate in chloroplasts prior to their transition to chromoplasts (Isaacson et al., 2002).

Similar phenomena are likely to occur when carotenoid biosynthesis in fruits chromoplasts is interrupted by inhibitors. Fruits or pericarp tissues at the mature green stage treated with norflurazon accumulate upon ripening excessive amounts of phytoene (Figure 4; Filler-Hayut, 2012). The buildup of phytoene, which was begun in the chloroplasts, possibly affected the assembly of membranes during the transition to chromoplasts in a manner that enabled PSY2 functioning. The difference in the carotenoid composition following treatment with norflurazon between ex-planta pericarp and whole fruit of yellow flesh (Figure 4) can be attributed to the diffusion of the inhibitor in the fruits during ripening that dilutes it to a low concentration that no longer blocks PDS. Moreover, the borders of the fully inhibited fruit sectors are diffused and sometimes unclear.

Similar to norflurazon, the lycopene cyclase inhibitor CPTA also induced carotenoid biosynthesis in fruits of yellow flesh $r^{3756}$ (Figure 5). Treatment with CPTA increased protein level of phytoene synthase in Narcissus pseudonarcissus flowers (Al-Babili et al., 1999) and caused transcriptional changes in Citrus sinensis (Lu et al., 2019). A slight increase of PSY2 expression was measured in CPTA-treated fruit sectors while PSY1 transcript levels were unchanged (Figure 5). However, since allele $r^{3756}$ carries a null mutation in PSY1, the induction of lycopene synthesis must have occurred due to activation of the PSY2 enzyme. In green tissues, CPTA eliminates cyclized carotenoids and leads to an accumulation of lycopene and other intermediate cis-carotenes (Fedtke et al., 2001; La Rocca et al., 2007). These changes in yellow flesh fruits treated with CPTA at the green stages could alter sub-organellar structures in the chloroplasts that linger during their transition to chromoplasts and influence PSY2 activity in ripening fruits. Activation of phytoene synthesis in fruits of yellow flesh mutants as a result of lycopene cyclase inhibition by CPTA has been recently reported by Gupta et al. (2022). The authors discovered that CPTA did not influence the expression levels of carotenoid biosynthesis genes and that ectopic accumulation of lycopene 
in chloroplasts was associated with the transition from chloroplasts to chromoplasts and the activation of PSY2 (Gupta et al., 2022). A comparable but slightly different case exists in pepper (Capsicum annuum) where PSY1 is the key enzyme responsible for fruit color and PSY2 functions in leaves (Berry et al., 2019; Dyachenko et al., 2020; Wei et al., 2020). However, it was demonstrated that PSY2 activity contributes to synthesizing a basal level of carotenoids in the fruit when PSY1 is not functional (Jang et al., 2020).

It has been established in Arabidopsis, melon, and sweet potato that the DnaJ chaperon protein ORANGE (Or) stabilizes PSY and regulates its activity by direct interaction between the two proteins (Zhou et al., 2015). Differential interaction of Or with paralogous PSY enzymes was reported in saffron (Ahrazem et al., 2020). The activation of PSY2 prompted by changes in the carotenoid composition may be enabled by a unique interaction of Or with PSY2 that either stabilizes the enzyme or interferes with its import to chromoplasts (Yuan et al., 2021).

Interestingly, disruption of carotenoid biosynthesis at $\zeta$-carotene in the mutant zeta $\left(z^{2083}\right)$ did not activate phytoene synthesis in yellow flesh fruits despite a significant accumulation of phytoene (Table 1; Kachanovsky et al., 2012). This phenomenon illustrates that only accumulation of a specific carotenoid intermediates are leading to activation of PSY2.

In conclusion, our results demonstrate that although PSY1 is the sole enzyme that produces phytoene in tomato fruit, under certain circumstances, PSY2 can be activated to sustain carotenoid biosynthesis. The results support the hypothesis on the existence of a carotenoid biosynthesis metabolon with distinct features in chloroplasts and chromoplasts. Furthermore, although transcriptional regulation is the primary mechanism determining carotenoid biosynthesis in tomato fruit, additional

\section{REFERENCES}

Ahrazem, O., Diretto, G., Argandona, P. J., Fiore, A., Rubio-Moraga, A., Rial, C., et al. (2019). The specialized roles in carotenogenesis and apocarotenogenesis of the phytoene synthase gene family in saffron. Front. Plant Sci. 10:249. doi: $10.3389 /$ fpls.2019.00249

Ahrazem, O., López, A. J., Argandoña, J., Castillo, R., Rubio-Moraga, Á., and Gómez-Gómez, L. (2020). Differential interaction of Or proteins with the PSY enzymes in saffron. Sci. Rep. 10:552. doi: 10.1038/s41598-020-57480-2

Alba, R., Payton, P., Fei, Z., McQuinn, R., Debbie, P., Martin, G. B., et al. (2005). Transcriptome and selected metabolite analyses reveal multiple points of ethylene control during tomato fruit development. Plant Cell 17, 2954-2965. doi: 10.1105/tpc.105.036053

Al-Babili, S., Hartung, W., Kleinig, H., and Beyer, P. (1999). CPTA modulates levels of carotenogenic proteins and their mRNAs and affects carotenoid and ABA content as well as chromoplast structure in Narcissus pseudonarcissus flowers. Plant Biol. 1, 607-612. doi: 10.1111/j.1438-8677.1999.tb00270.x

Alexander, L., and Grierson, D. (2002). Ethylene biosynthesis and action in tomato: a model for climacteric fruit ripening. J. Exp. Bot. 53, 2039-2055. doi: $10.1093 / \mathrm{jxb} / \mathrm{erf072}$

Ampomah-Dwamena, C., Driedonks, N., Lewis, D., Shumskaya, M., Chen, X., Wurtzel, E. T., et al. (2015). The Phytoene synthase gene family of apple (Malus $\times$ domestica) and its role in controlling fruit carotenoid content. BMC Plant Biol. 15:185. doi: 10.1186/s12870-015-0573-7

Arango, J., Wust, F., Beyer, P., and Welsch, R. (2010). Characterization of phytoene synthases from cassava and their involvement in abiotic stress- post-transcriptional mechanisms also play a role in this process. Additional future experiments that will determine the protein levels of PSY1 and PSY1 and their sub-organellar localization are required to elucidate the mechanism underlying the activation of PSY2 in fruit chromoplasts.

\section{DATA AVAILABILITY STATEMENT}

The original contributions presented in the study are included in the article/Supplementary Material, further inquiries can be directed to the corresponding author.

\section{AUTHOR CONTRIBUTIONS}

$\mathrm{UK}$ and $\mathrm{JH}$ conceptualize the research. UK, VM, and $\mathrm{NB}$ carried out the experiments. UK and JH wrote the manuscript. All authors contributed to the article and approved the submitted version.

\section{FUNDING}

This research was supported by the Israel Science Foundation Grant No. 1930/18.

\section{SUPPLEMENTARY MATERIAL}

The Supplementary Material for this article can be found online at: https://www.frontiersin.org/articles/10.3389/fpls.2022.844748/ full\#supplementary-material

mediated responses. Planta 232, 1251-1262. doi: 10.1007/s00425-0101250-6

Bergougnoux, V. (2014). The history of tomato: From domestication to biopharming. Biotechnol. Adv. 32, 170-189. doi: 10.1016/j.biotechadv.2013. 11.003

Berry, H. M., Rickett, D. V., Baxter, C. J., Enfissi, E. M. A., and Fraser, P. D. (2019). Carotenoid biosynthesis and sequestration in red chilli pepper fruit and its impact on colour intensity traits. J. Exp. Bot. 70, 2637-2650. doi: 10.1093/jxb/erz086

Bramley, P. M. (2002). Regulation of carotenoid formation during tomato fruit ripening and development. J. Exp. Bot. 53, 2107-2113. doi: 10.1093/jxb/ erf059

Butelli, E., Titta, L., Giorgio, M., Mock, H. P., Matros, A., Peterek, S., et al. (2008). Enrichment of tomato fruit with health-promoting anthocyanins by expression of select transcription factors. Nat. Biotechnol. 26, 1301-1308. doi: $10.1038 /$ nbt.1506

Cao, H., Luo, H., Yuan, H., Eissa, M. A., Thannhauser, T. W., Welsch, R., et al. (2019). A neighboring aromatic-aromatic amino acid combination governs activity divergence between tomato phytoene synthases. Plant Physiol. 180, 1988-2003. doi: 10.1104/pp.19.00384

Cazzonelli, C. I., Hou, X., Alagoz, Y., Rivers, J., Dhami, N., Lee, J., et al. (2020). A cis-carotene derived apocarotenoid regulates etioplast and chloroplast development. Elife 9:e45310. doi: 10.7554/eLife.45310.:e45310

Chen, L., Li, W., Li, Y., Feng, X., Du, K., Wang, G., et al. (2019). Identified trans-splicing of YELLOW-FRUITED TOMATO 2 encoding the PHYTOENE SYNTHASE 1 protein alters fruit color by map-based cloning, functional 
complementation and RACE. Plant Mol. Biol. 100, 647-658. doi: 10.1007/ s11103-019-00886-y

Chen, Y., Li, F., and Wurtzel, E. T. (2010). Isolation and characterization of the Z-ISO gene encoding a missing component of carotenoid biosynthesis in plants. Plant Physiol. 153, 66-79. doi: 10.1104/pp.110.153916

Cheng, X., Zhang, D., Cheng, Z., Keller, B., and Ling, H. Q. (2009). A new family of Ty1-copia-like retrotransposons originated in the tomato genome by a recent horizontal transfer event. Genetics 181, 1183-1193. doi: 10.1534/ genetics.108.099150

Chetelat, R. T. (2002). Revised list of monogenic stocks. Rep. Tomato Gene. $52,41-62$.

Cunningham, F. X., Chamovitz, D., Misawa, N., Gantt, E., and Hirschberg, D. (1993). Cloning and functional expression in Escherichia coli of a cyanobacterial gene for lycopene cyclase, the enzyme that catalyzes the biosynthesis of b-carotene. FEBS Lett. 328, 130-138.

Cunningham, F. X., and Gantt, E. (2007). A portfolio of plasmids for identification and analysis of carotenoid pathway enzymes: Adonis aestivalis as a case study. Photosynth. Res. 92, 245-259.

Cunningham, F. X., Pogson, B., Sun, Z. R., Mcdonald, K. A., Della Penna, D., and Gantt, E. (1996). Functional analysis of the b and e lycopene cyclase enzymes of Arabidopsis reveals a mechanism for control of cyclic carotenoid formation. Plant Cell 8, 1613-1626.

Cuttriss, A. J., Cazzonelli, C. I., Wurtzel, E. T., and Pogson, B. J. (2011). "Carotenoids" in Advances in Botanical Research: Biosynthesis of Vitamins in Plants Part A Vitamins A, B1, B2, B3, B5. ed. F. Rebeille (United States: Academic Press), 1-36.

Du, J., Tian, Z., Hans, C. S., Laten, H. M., Cannon, S. B., Jackson, S. A., et al. (2010). Evolutionary conservation, diversity and specificity of LTR-retrotransposons in flowering plants: insights from genome-wide analysis and multi-specific comparison. Plant J. 63, 584-598. doi: 10.1111/j.1365-313X.2010.04263.x

Dyachenko, E. A., Filyushin, M. A., Efremov, G. I., Dzhos, E. A., Shchennikova, A. V., and Kochieva, E. Z. (2020). Structural and functional features of phytoene synthase isoforms PSY1 and PSY2 in pepper Capsicum annuum L. cultivars. Vavilovskii. Zhurnal. Genet. Selektsii. 24, 687-696. doi: 10.18699/VJ20.663

Eggersdorfer, M., and Wyss, A. (2018). Carotenoids in human nutrition and health. Arch. Biochem. Biophys. 652, 18-26. doi: 10.1016/j.abb.2018.06.001.:18-26

Enfissi, E. M., Nogueira, M., Bramley, P. M., and Fraser, P. D. (2017). The regulation of carotenoid formation in tomato fruit. Plant J. 89, 774-788. doi: $10.1111 /$ tpj.13428

Escobar-Tovar, L., Sierra, J., McQuinn, R. P., Mathioni, S., Cordoba, E., Colas, D. F.-S., et al. (2020). Deconvoluting apocarotenoid-mediated retrograde signaling networks regulating plastid translation and leaf development. Plant J. 105, 1582-1599. doi: 10.1111/tpj.15134

Eshed, Y., and Zamir, D. (1995). An introgression line population of Lycopersicon pennellii in the cultivated tomato enables the identification and fine mapping of yield-associated QTL. Genetics 141, 1147-1162. doi: 10.1093/ genetics/141.3.1147

Fantini, E., Falcone, G., Frusciante, S., Giliberto, L., and Giuliano, G. (2013). Dissection of tomato lycopene biosynthesis through virus-induced gene silencing. Plant Physiol. 163, 986-998. doi: 10.1104/pp.113.224733

Fedtke, C., Depka, B., Schallner, O., Tietjen, K., Trebst, A., Wollweber, D., et al. (2001). Mode of action of new diethylamines in lycopene cyclase inhibition and in photosystem II turnover. Pest Manag. Sci. 57, 278-282. doi: $10.1002 /$ ps.296

Fernandez-Pozo, N., Zheng, Y., Snyder, S. I., Nicolas, P., Shinozaki, Y., Fei, Z., et al. (2017). The tomato expression atlas. Bioinformatics 33, 2397-2398. doi: 10.1093/bioinformatics/btx190

Filler-Hayut, S. (2012). Molecular characterization of the regulation of first steps in carotenoid biosynthesis pathway in tomato fruits. Master's thesis. Israel: The Hebrew University of Jerusalem.

Fraser, P. D., Enfissi, E. M., Halket, J. M., Truesdale, M. R., Yu, D., Gerrish, C., et al. (2007). Manipulation of phytoene levels in tomato fruit: effects on isoprenoids, plastids, and intermediary metabolism. Plant Cell 19, 3194-3211. doi: $10.1105 /$ tpc. 106.049817

Fraser, P. D., Kiano, J. W., Truesdale, M. R., Schuch, W., and Bramley, P. M. (1999). Phytoene synthase-2 enzyme activity in tomato does not contribute to carotenoid synthesis in ripening fruit. Plant Mol. Biol. 40, 687-698. doi: 10.1023/A:1006256302570
Fraser, P. D., Schuch, W., and Bramley, P. M. (2000). Phytoene synthase from tomato (Lycopersicon esculentum) chloroplasts-partial purification and biochemical properties. Planta 211, 361-369. doi: 10.1007/s004250000293

Fraser, P. D., Truesdale, M. R., Bird, C. R., Schuch, W., and Bramley, P. M. (1994). Carotenoid biosynthesis during tomato fruit development. Plant Physiol. 105, 405-413. doi: 10.1104/pp.105.1.405

Fray, R. G., and Grierson, D. (1993a). Identification and genetic analysis of normal and mutant phytoene synthase genes of tomato by sequencing, complementation and co-suppression. Plant Mol. Biol. 22, 589-602. doi: 10.1007/BF00047400

Fray, R. G., and Grierson, D. (1993b). Molecular genetics of tomato fruit ripening. Trends Genet. 9, 438-443. doi: 10.1016/0168-9525(93)90108-T

Gallagher, C. E., Matthews, P. D., Li, F., and Wurtzel, E. T. (2004). Gene duplication in the carotenoid biosynthetic pathway preceded evolution of the grasses. Plant Physiol. 135, 1776-1783. doi: 10.1104/pp.104.039818

Galpaz, N., Burger, Y., Lavee, T., Tzuri, G., Sherman, A., Melamed, T., et al. (2013). Genetic and chemical characterization of an EMS induced mutation in Cucumis melo CRTISO gene. Arch. Biochem. Biophys. 539, 117-125. doi: 10.1016/j.abb.2013.08.006

Gilbert, A. W. (1912). A Mendelian study of tomatoes. J. Hered. 1, 169-188. doi: 10.1093/jhered/os-7.1.169

Giorio, G., Stigliani, A. L., and D'Ambrosio, C. (2008). Phytoene synthase genes in tomato (Solanum lycopersicum L.) - new data on the structures, the deduced amino acid sequences and the expression patterns. FEBS J. 275, 527-535. doi: 10.1111/j.1742-4658.2007.06219.x

Giovannoni, J. (2001). Molecular biology of fruit maturation and ripening. Ann. Rev. Plant Physiol. Plant Mol. Biol. 52, 725-749. doi: 10.1146/annurev. arplant.52.1.725

Giovannoni, J. J. (2007). Fruit ripening mutants yield insights into ripening control. Curr. Opin. Plant Biol. 10, 283-289. doi: 10.1016/j.pbi.2007.04.008

Giovannoni, J., Nguyen, C., Ampofo, B., Zhong, S., and Fei, Z. (2017). The epigenome and transcriptional dynamics of fruit ripening. Annu. Rev. Plant Biol. 68, 61-84. doi: 10.1146/annurev-arplant-042916-040906

Gupta, P., Rodriguez-Franco, M., Bodanapu, R., Sreelakshmi, Y., and Sharma, R. (2022). Phytoene synthase 2 in tomato fruits remains functional and contributes to abscisic acid formation. Plant Sci. 316:111177. doi: 10.1016/j.plantsci.2022.111177

Hashimoto, H., Uragami, C., and Cogdell, R. J. (2016). "Carotenoids and photosynthesis," in Carotenoids in Nature: Biosynthesis, Regulation and Function. ed. C. Stange (Cham: Springer International Publishing), 111-139.

Hirschberg, J. (2001). Carotenoid biosynthesis in flowering plants. Curr. Opin. Plant Biol. 4, 210-218. doi: 10.1016/S1369-5266(00)00163-1

Hou, X., Rivers, J., Leon, P., McQuinn, R. P., and Pogson, B. J. (2016). Synthesis and function of Apocarotenoid signals in plants. Trends Plant Sci. 21, 792-803. doi: 10.1016/j.tplants.2016.06.001

Isaacson, T., Ohad, I., Beyer, P., and Hirschberg, J. (2004). Analysis in vitro of the enzyme CRTISO establishes a poly-cis carotenoid biosynthesis pathway in plants. Plant Physiol. 136, 4246-4255.

Isaacson, T. (2005). Molecular characterization of the carotenoid biosynthetic pathway in plants by cloning of genes for color mutations in tomato. $\mathrm{PhD}$ Thesis. Israel: The Hebrew University of Jerusalem.

Isaacson, T., Ronen, G., Zamir, D., and Hirschberg, J. (2002). Cloning of tangerine from tomato reveals a carotenoid isomerase essential for the production of b-carotene and xanthophylls in plants. Plant Cell 14, 333-342. doi: $10.1105 /$ tpc. 010303

Jang, S. J., Jeong, H. B., Jung, A., Kang, M. Y., Kim, S., Ha, S. H., et al. (2020). Phytoene synthase 2 can compensate for the absence of Psyl in capsicum fruit. J. Exp. Bot. 71, 3417-3427. doi: 10.1093/jxb/eraa155

Jenkins, J. A. (1948). The origin of the cultivated tomato. Econ. Bot. 2, 379-392. doi: $10.1007 / \mathrm{BF} 02859492$

Jiang, N., Visa, S. W. S., and Van der Knaap, E. (2012). "Rider transposon insertion and phenotypic change in tomato," in Plant Transposable Elements. Topics in Current Genetics. eds. M.-A. Grandbastien and J. M. Casacuberta (Heidelberg: Springer-Verlag), 298-312.

Joung, J. G., Corbett, A. M., Fellman, S. M., Tieman, D. M., Klee, H. J., Giovannoni, J. J., et al. (2009). Plant MetGenMAP: an integrative analysis system for plant systems biology. Plant Physiol. 151, 1758-1768. doi: 10.1104/ pp.109.145169

Kachanovsky, D. E., Filler, S., Isaacson, T., and Hirschberg, J. (2012). Epistasis in tomato color mutations involves regulation of phytoene synthase 1 expression 
by cis-carotenoids. Proc. Natl. Acad. Sci. U. S. A. 109, 19021-19026. doi: 10.1073/pnas.1214808109

Karniel, U., Koch, A., Zamir, D., and Hirschberg, J. (2020). Development of zeaxanthin-rich tomato fruit through genetic manipulations of carotenoid biosynthesis. Plant Biotechnol. J. 18, 2292-2303. doi: 10.1111/pbi.13387

Klee, H. J., and Giovannoni, J. J. (2011). Genetics and control of tomato fruit ripening and quality attributes. Annu. Rev. Genet. 45, 41-59. doi: 10.1146/ annurev-genet-110410-132507

La Rocca, N., Rascio, N., Oster, U., and Rüdiger, W. (2007). Inhibition of lycopene cyclase results in accumulation of chlorophyll precursors. Planta 225, 1019-1029. doi: 10.1007/s00425-006-0409-7

Lado, J., Zacarías, L., and Rodrigo, M. J. (2016). "Regulation of carotenoid biosynthesis during fruit development," in Carotenoids in Nature: Biosynthesis, Regulation and Function. ed. C. Stange (Cham: Springer International Publishing), 161-198.

Li, S., Chen, K., and Grierson, D. (2019). A critical evaluation of the role of ethylene and MADS transcription factors in the network controlling fleshy fruit ripening. New Phytol. 221, 1724-1741. doi: 10.1111/nph.15545

Li, F., Tsfadia, O., and Wurtzel, E. T. (2009). The phytoene synthase gene family in the grasses: subfunctionalization provides tissue-specific control of carotenogenesis. Plant Signal. Behav. 4, 208-211. doi: 10.4161/psb.4.3.7798

Li, F., Vallabhaneni, R., Yu, J., Rocheford, T., and Wurtzel, E. T. (2008). The maize phytoene synthase gene family: overlapping roles for carotenogenesis in endosperm, photomorphogenesis, and thermal stress tolerance. Plant Physiol. 147, 1334-1346. doi: 10.1104/pp.108.122119

Li, L., Yuan, H., Zeng, Y., and Xu, Q. (2016). "Plastids and carotenoid accumulation" in Carotenoids in Nature: Biosynthesis, Regulation and Function. ed. C. Stange (Cham: Springer International Publishing), 273-293.

Liu, Y. S., Gur, A., Ronen, G., Causse, M., Damidaux, R., Buret, M., et al. (2003). There is more to tomato fruit colour than candidate carotenoid genes. Plant Biotechnol. J. 1, 195-207. doi: 10.1046/j.1467-7652.2003.00018.x

Liu, L., Shao, Z., Zhang, M., and Wang, Q. (2015). Regulation of carotenoid metabolism in tomato. Mol. Plant 8, 28-39. doi: 10.1016/j.molp.2014.11.006

Llorente, B., Torres-Montilla, S., Morelli, L., Florez-Sarasa, I., Matus, J. T., Ezquerro, M., et al. (2020). Synthetic conversion of leaf chloroplasts into carotenoid-rich plastids reveals mechanistic basis of natural chromoplast development. Proc. Natl. Acad. Sci. U. S. A. 117, 21796-21803. doi: 10.1073/ pnas.2004405117

Lopez-Emparan, A., Quezada-Martinez, D., Zuniga-Bustos, M., Cifuentes, V., Iniguez-Luy, F., and Federico, M. L. (2014). Functional analysis of the Brassica napus L. phytoene synthase (PSY) gene family. PLoS One 9:e114878. doi: 10.1371/journal.pone.0114878

Lu, P., Wang, S., Grierson, D., and Xu, C. (2019). Transcriptomic changes triggered by carotenoid biosynthesis inhibitors and role of Citrus sinensis phosphate transporter 4;2 (CsPHT4;2) in enhancing carotenoid accumulation. Planta 249, 257-270. doi: 10.1007/s00425-018-2970-2

Maass, D., Arango, J., Wust, F., Beyer, P., and Welsch, R. (2009). Carotenoid crystal formation in Arabidopsis and carrot roots caused by increased phytoene synthase protein levels. PLoS One 4:e6373. doi: 10.1371/journal. pone. 0006373

McCue, G. A. (1952). The history of the use of the tomato: An annotated bibliography. Ann. Mo. Bot. Gard. 39, 289-384. doi: 10.2307/2399094

Menda, N., Semel, Y., Peled, D., Eshed, Y., and Zamir, D. (2004). In silico screening of a saturated mutation library of tomato. Plant J. 38, 861-872. doi: 10.1111/j.1365-313X.2004.02088.x

Neuman, H., Galpaz, N., Cunningham, F. X., Zamir, D., and Hirschberg, J. (2014). The tomato mutation $n x d 1$ reveals a gene necessary for neoxanthin biosynthesis and demonstrates that violaxanthin is a sufficient precursor for abscisic acid biosynthesis. Plant J. 78, 80-93.

Nisar, N., Li, L., Lu, S., Khin, N. C., and Pogson, B. J. (2015). Carotenoid metabolism in plants. Mol. Plant 8, 68-82. doi: 10.1016/j.molp.2014.12.007

Orzaez, D., Medina, A., Torre, S., Fernandez-Moreno, J. P., Rambla, J. L., Fernandez-Del-Carmen, A., et al. (2009). A visual reporter system for virusinduced gene silencing in tomato fruit based on anthocyanin accumulation. Plant Physiol. 150, 1122-1134. doi: 10.1104/pp.109.139006

Pankratov, I., McQuinn, R., Schwartz, J., Bar, E., Fei, Z., Lewinsohn, E., et al. (2016). Fruit carotenoid-deficient mutants in tomato reveal a function of the plastidial isopentenyl diphosphate isomerase (IDI1) in carotenoid biosynthesis. Plant J. 88, 82-94. doi: 10.1111/tpj.13232
Park, H., Kreunen, S. S., Cuttriss, A. J., DellaPenna, D., and Pogson, B. J. (2002). Identification of the carotenoid isomerase provides insight into carotenoid biosynthesis, prolamellar body formation, and photomorphogenesis. Plant Cell 14, 321-332. doi: 10.1105/tpc.010302

Pecker, I., Gabbay, R., Cunningham, F. X. Jr., and Hirschberg, J. (1996). Cloning and characterization of the cDNA for lycopene b-cyclase from tomato reveals decrease in its expression during fruit ripening. Plant Mol. Biol. 30, 807-819. doi: 10.1007/BF00019013

Price, H. L., and Drinkard, A. W. (1909). Inheritance in tomato hybrids. Plant World 12, 10-18.

Qin, X., Coku, A., Inoue, K., and Tian, L. (2011). Expression, subcellular localization, and cis-regulatory structure of duplicated phytoene synthase genes in melon (Cucumis melo L.). Planta 234, 737-748. doi: 10.1007/ s00425-011-1442-8

Rodriguez-Concepcion, M., Avalos, J., Bonet, M. L., Boronat, A., Gomez-Gomez, L., Hornero-Mendez, D., et al. (2018). A global perspective on carotenoids: metabolism, biotechnology, and benefits for nutrition and health. Prog. Lipid Res. 70, 62-93. doi: 10.1016/j.plipres.2018.04.004

Rodriguez-Villalon, A., Gas, E., and Rodriguez-Concepcion, M. (2009). Phytoene synthase activity controls the biosynthesis of carotenoids and the supply of their metabolic precursors in dark-grown Arabidopsis seedlings. Plant J. 60, 424-435. doi: 10.1111/j.1365-313X.2009.03966.x

Rosas-Saavedra, C., and Stange, C. (2016). "Biosynthesis of carotenoids in plants: enzymes and color," in Carotenoids in Nature: Biosynthesis, Regulation and Function. ed. C. Stange (Cham: Springer International Publishing), 35-69.

Ruiz-Sola, M. A., and Rodríguez-Concepción, M. (2012). Carotenoid biosynthesis in Arabidopsis: a colorful pathway. Arabidopsis Book 10:e0158. doi: 10.1199/ tab.0158

Sandmann, G., Schmidt, A., Linden, H., Hirschberg, J., and Boger, P. (1989). "Phytoene desaturase, a target for herbicidal inhibitors," in Biological Role of Plant Lipids. eds. P. A. Biacs, K. Gruiz and T. Kremmer (Boston, MA: Springer), 283-286.

Shinozaki, Y., Nicolas, P., Fernandez-Pozo, N., Ma, Q., Evanich, D. J., Shi, Y., et al. (2018). High-resolution spatiotemporal transcriptome mapping of tomato fruit development and ripening. Nat. Commun. 9, 364-02782. doi: 10.1038/s41467-017-02782-9

Shumskaya, M., Bradbury, L. M., Monaco, R. R., and Wurtzel, E. T. (2012). Plastid localization of the key carotenoid enzyme phytoene synthase is altered by isozyme, allelic variation and activity. Plant Cell 24, 3725-3741. doi: 10.1105/tpc.112.104174

Stauder, R., Welsch, R., Camagna, M., Kohlen, W., Balcke, G. U., Tissier, A., et al. (2018). Strigolactone levels in dicot roots are determined by an ancestral symbiosis-regulated clade of the PHYTOENE SYNTHASE gene family. Front. Plant Sci. 9:255. doi: 10.3389/fpls.2018.00255

Sun, T., Yuan, H., Cao, H., Yazdani, M., Tadmor, Y., and Li, L. (2018). Carotenoid metabolism in plants: The role of plastids. Mol. Plant 11, 58-74. doi: 10.1016/j. molp.2017.09.010

Tam, S. M., Causse, M., Garchery, C., Burck, H., Mhiri, C., and Grandbastien, M. A. (2007). The distribution of copia-type retrotransposons and the evolutionary history of tomato and related wild species. J. Evol. Biol. 20, 1056-1072. doi: 10.1111/j.1420-9101.2007.01293.x

Telfer, A. (2005). Too much light? How beta-carotene protects the photosystem II reaction Centre. Photochem. Photobiol. Sci. 4, 950-956. doi: 10.1039/ b507888c

Tomes, M. L., Quackenbush, F. W., Nelson, O. E., and North, B. (1953). The inheritance of carotenoid pigment system in the tomato. Genetics 38, 117-127.

Viguera, E., Canceill, D., and Ehrlich, S. D. (2001). In vitro replication slippage by DNA polymerases from thermophilic organisms. J. Mol. Biol. 312, 323-333. doi: 10.1006/jmbi.2001.4943

Von Lintig, J., and Quadro, L. (2020). Biology of carotenoids in mammals. Biochim. Biophys. Acta. Mol. Cell Biol. Lipids 1865:158754. doi: 10.1016/j. bbalip. 2020.158754

Walter, M. H., Stauder, R., and Tissier, A. (2015). Evolution of root-specific carotenoid precursor pathways for apocarotenoid signal biogenesis. Plant Sci. 233, 1-10. doi: 10.1016/j.plantsci.2014.12.017

Wang, J. Y., Lin, P. Y., and Al-Babili, S. (2020). On the biosynthesis and evolution of apocarotenoid plant growth regulators. Semin. Cell Dev. Biol. 109, 3-11. doi: 10.1016/j.semcdb.2020.07.007 
Wang, Z., Zhang, L., Dong, C., Guo, J., Jin, L., Wei, P., et al. (2021). Characterization and functional analysis of phytoene synthase gene family in tobacco. BMC Plant Biol. 21:32. doi: 10.1186/s12870-020-02816-3

Wei, X., Meng, C., Yuan, Y., Nath, U. K., Zhao, Y., Wang, Z., et al. (2020). CaPSY1 gene plays likely the key role in carotenoid metabolism of pepper (Capsicum annuum) at ripening. Funct. Plant Biol. 10, 141-155. doi: 10.1071/fp19287

Welsch, R., Wust, F., Bar, C., Al-Babili, S., and Beyer, P. (2008). A third phytoene synthase is devoted to abiotic stress-induced abscisic acid formation in rice and defines functional diversification of phytoene synthase genes. Plant Physiol. 147, 367-380. doi: 10.1104/pp.108.117028

Yuan, H., Pawlowski, E. G., Yang, Y., Sun, T., Thannhauser, T. W., Mazourek, M., et al. (2021). Arabidopsis ORANGE protein regulates plastid pre-protein import through interacting with tic proteins. J. Exp. Bot. 72, 1059-1072. doi: $10.1093 / \mathrm{jxb} / \mathrm{eraa} 528$

Zhao, W., Gao, L., Li, Y., Wang, M., Zhang, L., and Zhao, L. (2020). Yellowfruited phenotype is caused by $573 \mathrm{bp}$ insertion at 5' UTR of YFT1 allele in $y f t 1$ mutant tomato. Plant Sci. 300:110637. doi: 10.1016/j.plantsci.2020.110637

Zhou, X., Welsch, R., Yang, Y., Ãlvarez, D., Riediger, M., Yuan, H., et al. (2015). Arabidopsis OR proteins are the major posttranscriptional regulators of phytoene synthase in controlling carotenoid biosynthesis. Proc. Natl. Acad. Sci. U. S. A. 112, 3558-3563. doi: 10.1073/pnas.1420831112

Conflict of Interest: The authors declare that the research was conducted in the absence of any commercial or financial relationships that could be construed as a potential conflict of interest.

Publisher's Note: All claims expressed in this article are solely those of the authors and do not necessarily represent those of their affiliated organizations, or those of the publisher, the editors and the reviewers. Any product that may be evaluated in this article, or claim that may be made by its manufacturer, is not guaranteed or endorsed by the publisher.

Copyright (c) 2022 Karniel, Adler Berke, Mann and Hirschberg. This is an open-access article distributed under the terms of the Creative Commons Attribution License (CC BY). The use, distribution or reproduction in other forums is permitted, provided the original author(s) and the copyright owner(s) are credited and that the original publication in this journal is cited, in accordance with accepted academic practice. No use, distribution or reproduction is permitted which does not comply with these terms. 